\title{
Mechanosensitive ion channel Piezo1 promotes prostate cancer development through the activation of the Akt/mTOR pathway and acceleration of cell cycle
}

\author{
YU HAN ${ }^{1-4}$, CHAO LIU ${ }^{5,6}$, DONGFANG ZHANG ${ }^{1-4}$, HONGCHAO MEN $^{1-4}$, LIFANG HUO $^{2,3,7}$, QIAOWEI GENG ${ }^{1-4}$, \\ SHENGNAN WANG ${ }^{1-4}$, YITING GAO ${ }^{1-4}$, WEI ZHANG ${ }^{2,3,7}$, YONGJIAN ZHANG ${ }^{1-4}$ and ZHANFENG JIA ${ }^{1-4}$ \\ ${ }^{1}$ Department of Pharmacology, ${ }^{2}$ Center for Innovative Drug Research and Evaluation, Institute of Medical Science and Health, \\ Hebei Medical University; ${ }^{3}$ The Key Laboratory of Neural and Vascular Biology, Ministry of Education; \\ ${ }^{4}$ The Key Laboratory of New Drug Pharmacology and Toxicology; ${ }^{5}$ Department of Laboratory Animal Science, \\ ${ }^{6}$ Hebei Key Lab of Hebei Laboratory Animal Science, ${ }^{7}$ Department of Pharmacology, \\ Institute of Chinese Integrative Medicine, Hebei Medical University, Shijiazhuang, Hebei 050017, P.R. China
}

Received January 24, 2019; Accepted July 1, 2019

DOI: $10.3892 /$ ijo.2019.4839

\begin{abstract}
Prostate cancer is one of the most common types of cancer affecting men worldwide; however, its etiology and pathological mechanisms remain poorly understood. Mechanical stimulation plays a key role in prostate cancer development. Piezo type mechanosensitive ion channel component 1 (Piezo1), which functions as a cell sensor and transducer of mechanical stimuli, may have a crucial role in the development of prostate cancer. In the present study, the expression of the Piezol channel was demonstrated to be significantly elevated in prostate cancer cell lines and in human prostate malignant tumor tissues. Downregulation of Piezol significantly suppressed the viability, proliferation and migration of prostate cancer cells in vitro, and inhibited prostate tumor growth in vivo. The activation of the $\mathrm{Akt} / \mathrm{mTOR}$ pathway or acceleration of cell cycle progression from $\mathrm{G}_{0} / \mathrm{G}_{1}$ to $\mathrm{S}$ phase may downstream consequences of Piezo 1 signal pathway activation. Downregulation of Piezol considerably suppressed $\mathrm{Ca}^{2+}$ signal increments, inhibited the phosphorylation of Akt and mTOR and arrested the cell cycle of prostate cancer cells at $\mathrm{G}_{0} / \mathrm{G}_{1}$ phase in while inhibiting the activation of CDK4 and cyclin D1. Taken together, these findings suggest that Piezo1 channels have a crucial role in prostate cancer development and may, therefore, be a novel therapeutic target in the treatment of prostate cancer.
\end{abstract}

Correspondence to: Professor Yongjian Zhang or Professor Zhanfeng Jia, Department of Pharmacology, Hebei Medical University, 361 Zhongshan East Road, Shijiazhuang, Hebei 050017, P.R. China

E-mail: yizhang_hebmu@163.com

E-mail: jiazf@hebmu.edu.cn

Key words: Piezo type mechanosensitive ion channel component 1, prostate cancer, $\mathrm{Ca}^{2+}$ signal, Akt/mTOR pathway, cell cycle

\section{Introduction}

Prostate cancer $(\mathrm{PCa})$ is one of the most common types of cancer in men worldwide. In the United States, PCa is the most frequent malignancy and the third common cause of cancer-related death in males $(1,2)$. However, the etiology and pathological mechanisms of $\mathrm{PCa}$ require extensive investigation, despite the current knowledge on the several risk factors that may affect its origin and development (3-5). In addition to genetic, biochemical and metabolic events, biomechanical factors, such as the integrated forces within tissues, also have an important role in tumor development (6,7). Previous studies have shown that pressure is significantly higher in human prostates with cancer than in normal tissues (8), prostate epithelial cells and stromal cells, and may confer resistance to apoptosis $(9,10)$. Tumor-induced pressure in the bone microenvironment is also known to promote PCa bone metastasis growth (11). Given that increased prostate pressure may play a key role in the pathogenesis of PCa (8-11), Piezo channels, which act as cell sensors and mechanotransduction mediators, may have an important role in PCa development.

Piezo channels, including piezo type mechanosensitive ion channel component 1 and 2 (Piezo1 and Piezo2), were identified in 2010 as the long sought-after molecular carriers of mechanically activated currents in many cells $(12,13)$. Piezo channels are essential for detecting external mechanical stimuli, as well as for sensing mechanical forces within tissues (such as lung expansion and blood flow) (14-18). In addition to mechanotransduction, Piezo1 channels also have an important role in cell neogenesis, survival, differentiation and proliferation $(13,18)$. For instance, Piezol channels facilitate the migration and alignment of endothelial cells in response to shear stress induced by blood flow, and disruption of Piezo1 profoundly disturbs the developing vasculature $(16,19)$. In epithelial cells, the opening of Piezol channels induced by mechanical stretching is followed by $\mathrm{Ca}^{2+}$ influx, which activates the $\mathrm{Ca}^{2+}$-sensitive ERK1, in turn promoting cell proliferation (20). Proliferation and differentiation of stem 
cells in the fly midgut are also triggered by Piezol channel activation (21). As a trefoil factor family 1 (TFF1)-binding protein, Piezo1 promotes TFF1-mediated migration and invasion of gastric cancer cells (22). Given that Piezo1 significantly promotes cell proliferation and migration, it was hypothesized that Piezol and its downstream signaling pathways may have an important role in the development of PCa.

In the present study, the expression level of Piezol channel was found to be significantly higher in DU145 and PC3 PCa cell lines, as well as in human prostate malignant tumors compared to non-malignant tissues. The downregulation of Piezol channel suppressed the proliferation and migration of PCa cells, as well as the growth prostate tumors inoculated in nude mice. Akt/mTOR activation and acceleration of cell cycle progression may have been responsible for Piezol-induced progression of $\mathrm{PCa}$. Taken together, the present study strongly suggests that Piezol channels have a crucial role in $\mathrm{PCa}$ development. Piezol could be a novel therapeutic target in clinical treatment of PCa.

\section{Materials and methods}

Reagents and antibodies. Antibodies specific to Piezo1 (cat. no. 15939-1-AP), $\beta$-actin (cat. no. 66009-1-Ig), CDK4 (cat. no. 11026-1-AP), cyclin D1 (cat. no. 60186-1-Ig), and platelet and endothelial cell adhesion molecule 1 (CD31; cat. no. 11265-1-AP) were purchased from ProteinTech Group, Inc. (dilution, 1:1,000). Antibodies specific to proliferating cell nuclear antigen (PCNA; cat. no. 2714-1) and phosphorylated (p-)AKT (Ser473; cat. no. 2118-S) were purchased from Epitomics (dilution, 1:500; Abcam). Antibodies specific to AKT (cat. no. GB13011-2), PI3K (cat. no. GB13161) and Ki-67 (cat. no. GB13030-2) were purchased from Wuhan Servicebio Technology Co., Ltd. (dilution, 1:500). The antibodies against p-mTOR (cat. no. 5536T) and mTOR (cat. no. 2972S) were purchased from Cell Signal Technology, Inc. (dilution, 1:1,000). Antibodies specific to ERK (cat. no. AF0155) and p-ERK (Thr202/Tyr204; cat. no. AF1015) were purchased from Affinity Biosciences (dilution, 1:500). Lastly, the mechanosensitive and stretch-activated ion channel inhibitor, GsMTx4 (cat. no. ab141871), was obtained from Abcam.

Cell culture. The RWPE-1, PC3, and DU145 cell lines were purchased from the Shanghai Institutes for Biological Sciences. RWPE-1 was maintained in K-SFM medium (Thermo Fisher Scientific, Inc.). The PC3 and DU145 cells were maintained in RPMI-1640 medium (Thermo Fisher Scientific, Inc.) containing $10 \% \mathrm{FBS}$ with $100 \mathrm{IU} / \mathrm{ml}$ penicillin and $0.1 \mathrm{mg} / \mathrm{ml}$ streptomycin. Cell cultures were maintained in a humidified atmosphere of $95 \%$ air and $5 \% \mathrm{CO}_{2}$ at $37^{\circ} \mathrm{C}$. All cell lines showed no signs of mycoplasma contamination.

Establishment of Piezol knockdown. The target sequence of short hairpin RNA (shRNA) 1 and shRNA2 were, respectively, 5'-cccugugc auugauuaucccu-3' and 5'-AGAAGAAGAUCGUC AAGUA-3' (23). The sequence of the non-targeting control shRNA is 5'-CCUAAGGUUAAGUCGCCCUC-3'. The lentiviral vector pLKO.1 (obtained from Department of Pharmacology, Hebei Medical University) was used to construct Piezo1 shRNA1, Piezo1 shRNA2 and control shRNA lentivirus. The titer of lentivirus was up to $107 \mathrm{TU} / \mathrm{ml}, 500 \mu \mathrm{l}$ lentivirus used to infect cells in $35 \mathrm{~mm}$ petri dishes. Lentivirus-infected DU145 cells were screened with $1 \mu \mathrm{g} / \mathrm{ml}$ puromycin to establish Piezo1 shRNA1 DU145, Piezo1 shRNA2 DU145 and control shRNA DU145 cells.

Whole-cell patch clamp recording. Whole-cell patch clamp recordings were performed at a room temperature of $22-24^{\circ} \mathrm{C}$ with $1 \times 10^{4}$ cells seeded on coverslips. Coverslips with cultured cells were placed in a $0.5 \mathrm{ml}$ microchamber, mounted on the stage of an Olympus IX71 inverted microscope (Olympus Corporation) and continuously perfused at $2 \mathrm{ml} / \mathrm{min}$ with bath solution. The bath solution contained $145 \mathrm{mM} \mathrm{NaCl}$, $5 \mathrm{mM} \mathrm{KCl}, 2 \mathrm{mM} \mathrm{MgCl}, 2 \mathrm{mM} \mathrm{CaCl}, 10 \mathrm{mM}$ glucose and $10 \mathrm{mM}$ HEPES, with an osmolarity $320 \mathrm{mOsm}$ and $\mathrm{pH} 7.35$. The recording pipette solution contained $135 \mathrm{mM}$ K-gluconate, $5 \mathrm{mM} \mathrm{KCl}, 2.4 \mathrm{mM} \mathrm{MgCl} 2,0.5 \mathrm{mM} \mathrm{CaCl} 2,5 \mathrm{mM}$ EGTA, $10 \mathrm{mM}$ HEPES, $5 \mathrm{mM} \mathrm{NaCl}, 2 \mathrm{mM}$ ATP and $0.33 \mathrm{mM}$ NaGTP, with pH 7.35 and osmolarity 320 mOsm. The recording electrodes were built from thin wall borosilicate glass capillaries using a Flaming P-97 puller (Sutter Instrument Company) and had resistances of 2-4 M $\Omega$. The protocol used to study Piezo mechanically activated (MA) currents in tumor cells was as follows: The cells were held at $-60 \mathrm{mV}$ and cell membranes were displaced by heat-polished glass probe. The probe, with a $\sim 4 \mu \mathrm{m}$ diameter tip, was positioned at an angle of $45^{\circ}$ to the dish surface and its movement was controlled by a Piezo-electric device (Physik Instrumente, Ltd.). Cells were stimulated with a series of mechanical stimuli in $1 \mu \mathrm{m}$ increments to elicit Piezo MA currents. The moving velocity of the probe was set at $0.5 \mu \mathrm{m} / \mathrm{ms}$. Signals were recorded with an Axonpatch 700B amplifier, filtered at $2 \mathrm{kHz}$ and sampled at $5 \mathrm{kHz}$ using pClamp 10.7 (Axon Instruments; Molecular Devices, LLC).

Cell proliferation assays. Cells were seeded at a density of $6 \times 10^{3}$ cells/well into a 96 -well plate $(150 \mu \mathrm{l} / \mathrm{well})$. Cell proliferation ability was examined using a Cell Proliferation Assay (MTS; Promega Corporation), according to the manufacturer's instructions. Colony formation assays were performed to monitor the PCa cells cloning capability. Cells were seeded into a 6 -well plate at a density of 800 cells per well. After incubation for 12 days, visible colonies were fixed with $100 \%$ methanol at room temperature for $10 \mathrm{~min}$, stained with $5 \mathrm{mg} / \mathrm{ml}$ crystal violet at room temperature for $20 \mathrm{~min}$, counted and normalized to control group. All experiments were repeated at least three times.

Transwell assay. The lower chamber of Transwell ${ }^{\circledR}$ was filled with medium containing $10 \%$ FBS. Cells were digested and suspended in medium without serum and $4 \times 10^{3}$ cells were placed in the upper chamber of a Transwell ${ }^{\circledR}$ (Corning, Inc.). After a 48-h incubation, with or without GsMTx4 $(4 \mu \mathrm{M})$, the cells were fixed with $4 \%$ formalin, at room temperature for $10 \mathrm{~min}$, then stained with $5 \mathrm{mg} / \mathrm{ml}$ crystal violet at room temperature for $20 \mathrm{~min}$. Five random visual fields were imaged, and cells were counted. Experiments were repeated at least three times.

Wound-healing assay. A linear wound was made using $200 \mu 1$ pipette tips across a culture of confluent cells. Cells 
$\left(2 \times 10^{5}\right.$ cells/well) were cultured in 12 -well plates, and allowed to grow to $80-90 \%$ confluence. Then cells treated with or without GsMTx4 $(4 \mu \mathrm{M})$ for $48 \mathrm{~h}$, were imaged after incubation with serum-free medium for 0,24 or $48 \mathrm{~h}$. The wound area was calculated at 0,24 and $48 \mathrm{~h}$ after scratching using ImageJ 1.50i software (National Institutes of Health) to assess the cell migration during wound closure. Experiments were repeated at least three times.

Cell-cycle analysis. Cells $\left(1 \times 10^{6}\right.$ cells) were fixed with $70 \%$ ethanol at $4^{\circ} \mathrm{C}$ overnight, treated with $100 \mu \mathrm{g} / \mathrm{ml}$ stock of RNase and stained with $50 \mu \mathrm{g} / \mathrm{ml}$ of propidium iodide. The stained cells were analyzed by flow cytometry (BD Biosciences), and the results were analyzed using the Expo32 ADC analysis software version 1.1C (BD Biosciences).

Calcium imaging. Cells $\left(1 \times 10^{5}\right)$ were loaded with $2 \mu \mathrm{M}$ fluo-4-acetoxymethyl ester (fluo-4-AM; Molecular Probes; Thermo Fisher Scientific, Inc.) at $37^{\circ} \mathrm{C}$ for $30 \mathrm{~min}$. After loading, the cells were washed three times with Dulbecco's PBS to remove the extracellular dye, and then placed in a chamber mounted on the stage of laser scanning confocal microscope (Leica TCS SP5; Leica Microsystems $\mathrm{GmbH}$ ). The cells were incubated with the same bath solution as the patch clamp experiment. Fluo-4-AM loaded calcium signals were excited at a wavelength of $488 \mathrm{~nm}$, and the emission fluorescence was measured at $530 \mathrm{~nm}$. The calcium signals from the Piezol channel induced by treatment with its agonist Yoda1 and the mechanically induced calcium signals were measured. Yodal was applied in bath solution at $1 \mu \mathrm{M}$ to induce intracellular calcium signals. The protocol for mechanical stimulation to induce calcium signals was identical to the protocol used for recording Piezo1 MA currents with whole-cell patch clamp and cells were stimulated with a series of mechanical stimuli in $1 \mu \mathrm{m}$ increments to elicit calcium signals. Dynamic signals were recorded at an interval of two seconds and normalized to the initial fluorescence value. The area under curve (AUC), which means the area between the curve and basal line axis along the time course, was calculated with Origin 9.1 software (OriginLab).

Reverse transcription-quantitative PCR (rt-qPCR). Total RNA was extracted from the cells using RNAiso Plus total RNA extraction reagent (Takara Bio, Inc.). cDNA was synthesized using a PrimeScript RT reagent Kit with gDNA Eraser (Takara Bio, Inc., Otsu, Japan). Genomic DNA is eliminated by treatment with gDNA Eraser for $2 \mathrm{~min}$ at $42^{\circ} \mathrm{C}$. The reaction conditions were as follows: $37^{\circ} \mathrm{C}$ for $15 \mathrm{~min}, 85^{\circ} \mathrm{C}$ for $5 \mathrm{sec}$ and $4^{\circ} \mathrm{C}$ for termination. Subsequently, cDNA was and stored at $-20^{\circ} \mathrm{C}$. qPCR was performed using a SYBR Premix Ex Taq Real-Time PCR Kit (Takara Bio, Inc.). The reaction conditions were one cycle of initial denaturation at $95^{\circ} \mathrm{C}$ for $3 \mathrm{~min}$, followed by 40 cycles of $95^{\circ} \mathrm{C}$ for $30 \mathrm{sec}, 60^{\circ} \mathrm{C}$ for $30 \mathrm{sec}$. The PCR primer sequences were as follows: Piezo1, forward 5'-ATGTTGCTCTACACCCTGACC-3' and reverse 5'-CCAGCACACACATAGATCCAGT-3'; GAPDH, forward 5'-GGCATGGACTGTGGTCATGAG-3' and reverse 5'-TGCACCACCAACTGCTTAGC-3'. GAPDH was used as the internal reference gene. Each test was performed in triplicate and the $2^{-\Delta \Delta \mathrm{Cq}}$ method was used to calculate gene expression (24).
Determination of PI3K activity. The activity of PI3K was measured based on the amount of NADH using the GENMED PI3K Assay Kit (Genmed Scientifics, Inc.). The cells were harvested and processed according to manufacturer's instructions. Protein concentration was determined using the bicinchoninic acid protein assay kit (Beyotime Institute of Biotechnology). The absorbance of the negative control and samples was detected at a wavelength of $340 \mathrm{~nm}$ at 0 and 5 min using a microplate reader (Thermo Fisher Scientific, Inc.). The amount of NADH $(\mu \mathrm{mol} / \mathrm{min} / \mathrm{mg})$ was calculated using the protein concentration.

Western blot analysis. Total proteins extracted from cells using RIPA lysis buffer (Beyotime Institute of Biotechnology). The concentrations of proteins were detected using a bicinchoninic acid protein kit (Beyotime Institute of Biotechnology). Protein samples $(20 \mu \mathrm{g})$ were loaded onto $8 \%$ gels and separated by SDS-PAGE. The resolved proteins were electrophoretically transferred to PVDF membranes. To evaluate proteins levels, the blots were blocked with 5\% non-fat milk in TBS with Tween-20 at room temperature for $1 \mathrm{~h}$ and incubated with primary antibodies. $\beta$-actin was used as the internal control. The blots were then probed with secondary antibodies (IRDye 800CW goat anti-rabbit, cat. no. 926-32210; IRDye 800CW goat anti-mouse, cat. no. 926-32211; LI-COR Biosciences), and the blots visualized using the Odyssey Fc System (LI-COR Biosciences). Densitometry of the protein bands was performed using ImageJ 1.50i software (National Institutes of Health). The experiments were repeated at least three times.

In vivo xenograft tumor growth. Male Balb/c nu/nu mice (3-4 weeks of age; weight, 12.6-15.4 g; 7 mice/group; 21 mice in total) were purchased from Beijing Vital River Laboratory Animal Technology Co., Ltd. (Beijing, China) and kept at temperature $\left(22-24^{\circ} \mathrm{C}\right)$ with a stable humidity $(55 \pm 15 \%)$ with free access to food/water in a $12 \mathrm{~h} / 12 \mathrm{~h}$ light/dark cycle, according to the guidelines of the local Animal Care and Use Committee at Hebei Medical University. A total of $1 \times 10^{7}$ Piezol shRNA1 cells and $1 \times 10^{7}$ control shRNA cells were injected subcutaneously into the right dorsonuchal area of the nude mice, with seven animals being included in each injection group. The tumors were measured every 7 days for 4 weeks, and tumor size was calculated as follows: $\left(\mathrm{a} \mathrm{x} \mathrm{b}^{2}\right) / 2$, where $a$ and $b$ are the longest longitudinal and transverse diameters, respectively. The endpoint of the experiments was the 28th day after injection. The mice were euthanized, and the tumors were removed, weighed, imaged and fixed with $4 \%$ paraformaldehyde at room temperature for $24 \mathrm{~h}$. A total of 10 consecutive $4 \mu \mathrm{m}$-thick sections were prepared for hematoxylin-eosin (HE) staining. The sections were stained with $0.2 \%$ hematoxylin staining solution (Sangon Biotech Co., Ltd.) for $5 \mathrm{~min}$ at room temperature, then stained with $0.5 \%$ eosin staining solution (Sangon Biotech Co., Ltd.) for $3 \mathrm{~min}$ at room temperature. Images were acquired using a Leica microscope (Leica DM6000B; LAS V.4.3; Leica Microsystems, GmbH).

Bioluminescence imaging in vivo To obtain luciferase-labeled DU145 cells, $2 \times 10^{5}$ DU145 cells were transfected with $10 \mu \mathrm{l}$ 
LV-luc-puro lentivirus (1x10 $10^{8} \mathrm{TU} / \mathrm{ml}$ ) (Hanbio Biotechnology Co., Ltd.). A total of $1 \times 10^{7}$ luciferase-labeled DU145 cells, obtained by transducing with LV-luc-puro lentiviral were inoculated hypodermically into the right dorsonuchal area of nude mice (nu/nu; male; 3-4 weeks of age; weight, 12.8-15.2 g; 5 mice/group; 25 mice in total; Vital River Laboratory Animal Technology Co., Ltd.). The mice were housed at temperature $\left(22-24^{\circ} \mathrm{C}\right)$ with a stable humidity $(55 \pm 15 \%)$ with free access to food/water in a $12 \mathrm{~h} / 12 \mathrm{~h}$ light/dark cycle. AAV-Piezo1-shRNA1-DsRed2 and AAV-DsRed2 were manufactured by Hanbio Biotechnology Co., Ltd., and the former was used to deliver shRNA1-targeted Piezol to the tumor site. When tumor size reached $\sim 100 \mathrm{~mm}^{3}$, which occurred around the 14th day, the mice were randomly assigned to five groups. In four of the groups, mice were separately treated with AAV-Piezo1-shRNA1-DsRed2, AAV-DsRed2, saline or GsMTx4. The mice in the other group were left untreated (blank). The injection of virus was administered on the 18th, 20th, 22nd, 24th and 28th days after tumor cell implantation. For each injection, $17 \mu 1$ of either AAV-Gluc-DsRed 2 or AAV-S-TRAIL ( $10^{12}$ virus particles $\left./ \mathrm{ml}\right)$ were injected directly into the tumor mass. Direct intra-tumor injections of GsMTx4 $(12.5 \mu \mathrm{l}$ at $400 \mathrm{pmol})$ or $\mathrm{NaCl}(12.5 \mu \mathrm{l})$ took place at the 18th, 20th, 22nd, 24th and 28th day after tumor cell implantation.

Bioluminescence images were acquired with a Berthold LB983 NC320 NightOwl System (Berthold Technologies $\mathrm{GmbH} \& \mathrm{Co} . \mathrm{KG}$ ) and were used to serially monitor changes of tumor volume. The mice were imaged for luciferase activity on days 17, 24, 31 and 38 after implantation of LV-luc-puro transduced DU145 cells. The mice were intraperitoneally injected with D-luciferin $(150 \mathrm{mg} / \mathrm{kg}$ body weight), and the tumors were imaged $10 \mathrm{~min}$ after injection at a 20 -sec exposure time. The study protocol was approved by Animal Care and Use Committee at Hebei Medical University (Shijiazhuang, China).

Immunohistochemical (IHC) staining. Human PCa tissue array (Wuhan Servicebio Technology Co., Ltd.; cat. no. 1677234) contains 26 cases of paracarcinoma tissues and 44 cases of carcinoma tissues with Gleason scores from 6 to 10 (25). One patient had regional lymph node metastasis. All samples were from patients within the age range of 28-87 years. Tissues were fixed in $4 \%$ formalin at room temperature for $24 \mathrm{~h}$ and dehydrated with 75, 95 and 100\% ethanol and xylene. Samples were embedded in paraffin and sliced into $4 \mu \mathrm{m}$-thick sections. For IHC, sections were deparaffinized in xylene, rehydrated in 100, 95 and $75 \%$ ethanol, and distilled water, and then a microwave was used for antigen retrieval. The sections were subsequently soaked in $0.3 \% \mathrm{H}_{2} \mathrm{O}_{2}$ to block the activities of endogenous peroxidases and subsequently incubated with $10 \%$ goat serum (Sangon Biotech Co., Ltd.) for $1 \mathrm{~h}$ to prevent the occurrence of non-specific reactions, all at room temperature. Subsequently, the sections were incubated with primary antibody at $4^{\circ} \mathrm{C}$ for $12 \mathrm{~h}$. Antibodies to Piezo1 (cat. no. 15939-1-AP; dilution, 1:250) and CD31 (cat. no. 11265-1-AP; dilution, 1:1000) were purchased from ProteinTech Group, Inc. Antibody specific to proliferating cell nuclear antigen PCNA (cat. no. 2714-1; dilution, 1:200) was purchased from Epitomics (dilution, 1:500; Abcam). Antibody specific to Ki-67 (cat. no. GB13030-2; dilution, 1:300) was purchased from Wuhan Servicebio Technology
Table I. Expression of Piezo1 channel in human prostate carcinoma tissues and prostate paracarcinoma tissues.

\begin{tabular}{lccrc}
\hline \multirow{2}{*}{ Group } & \multicolumn{4}{c}{$\begin{array}{c}\text { Piezo1 } \\
\text { expression }\end{array}$} \\
\cline { 2 - 4 } & $\begin{array}{c}\text { Number of } \\
\text { patients }\end{array}$ & Low & High & P-value \\
\hline Paracarcinoma tissue & 26 & 22 & 4 & 0.000008 \\
Carcinoma tissue & 44 & 13 & 31 & \\
\hline
\end{tabular}

$\chi^{2}$ test was used to analyze the difference of Piezo1 expression between human prostate carcinoma tissues and prostate paracarcinoma tissues. Piezo1, piezo type mechanosensitive ion channel component 1.

Co., Ltd. Immunostaining was performed using the SP Immunohistochemical commercial assay kit (cat. no. SP-900; Beijing Zhongshan Jinqiao Biotechnology Co., Ltd.) according to the manufacturer's instructions. They were then incubated with kit's biotinylated secondary antibody at $37^{\circ} \mathrm{C}$ for $1 \mathrm{~h}$, and streptavidin/peroxidase complex working solution for $1 \mathrm{~h}$. Peroxidase staining using a diaminobenzidine kit (Dako; Agilent Technologies, Inc.). Nuclear couterstain were stained with $0.2 \%$ hematoxylin staining solution (Sangon Biotech Co., Ltd.) for $1 \mathrm{~min}$ at room temperature. After IHC staining, tissue specimen/samples were scanned with Pannoramic MIDI (3DHISTECH, Ltd.) and analyzed with a Pannoramic viewer (3DHISTECH, Ltd.). The percentage and intensity of immunostaining were recorded, and the $\mathrm{H}$-score was calculated using the following formula: $\mathrm{H}$ score $=\Sigma(\mathrm{PIxI})=$ (percentage of cells of weak intensity $x 1)+($ percentage of cells of moderate intensity $\mathrm{x} 2$ ) + percentage of cells of strong intensity $\mathrm{x} 3$ ). The highest possible $\mathrm{H}$-score is 300 , and an expression above the median was defined as high expression, while an expression below the median was considered low expression (26).

Statistical analysis. Data are presented as the mean \pm SEM for the indicated number of independently conducted experiments, and analyzed with SPSS (SPSS, Inc.). Statistical significance was evaluated using either a Student's t-test or a one-way analysis of variance followed by Dunnett's post hoc test for multiple groups. A $\chi^{2}$ test was used to analyze the human tissue arrays. $\mathrm{P}<0.05$ was considered to indicate a statistically significant difference.

\section{Results}

Piezol is upregulated in human PCa tissues and cell lines. To determine the expression of Piezol channel in human prostate tissues, human prostate tissue arrays were evaluated by IHC staining. There were 44 cases of prostate carcinoma tissues and 26 cases of benign tissues adjacent to $\mathrm{PCa}$ areas (paracarcinoma). Piezol channel was highly expressed in PCa tissues compared to paracarcinoma tissues (Fig. 1A), together with a significant higher $\mathrm{H}$-score for Piezol expression in prostate carcinoma tissues (Fig. 1B).

Tissues array analysis indicated that the Piezol channel was upregulated in 31 out of 44 patients with PCa (Table I). 

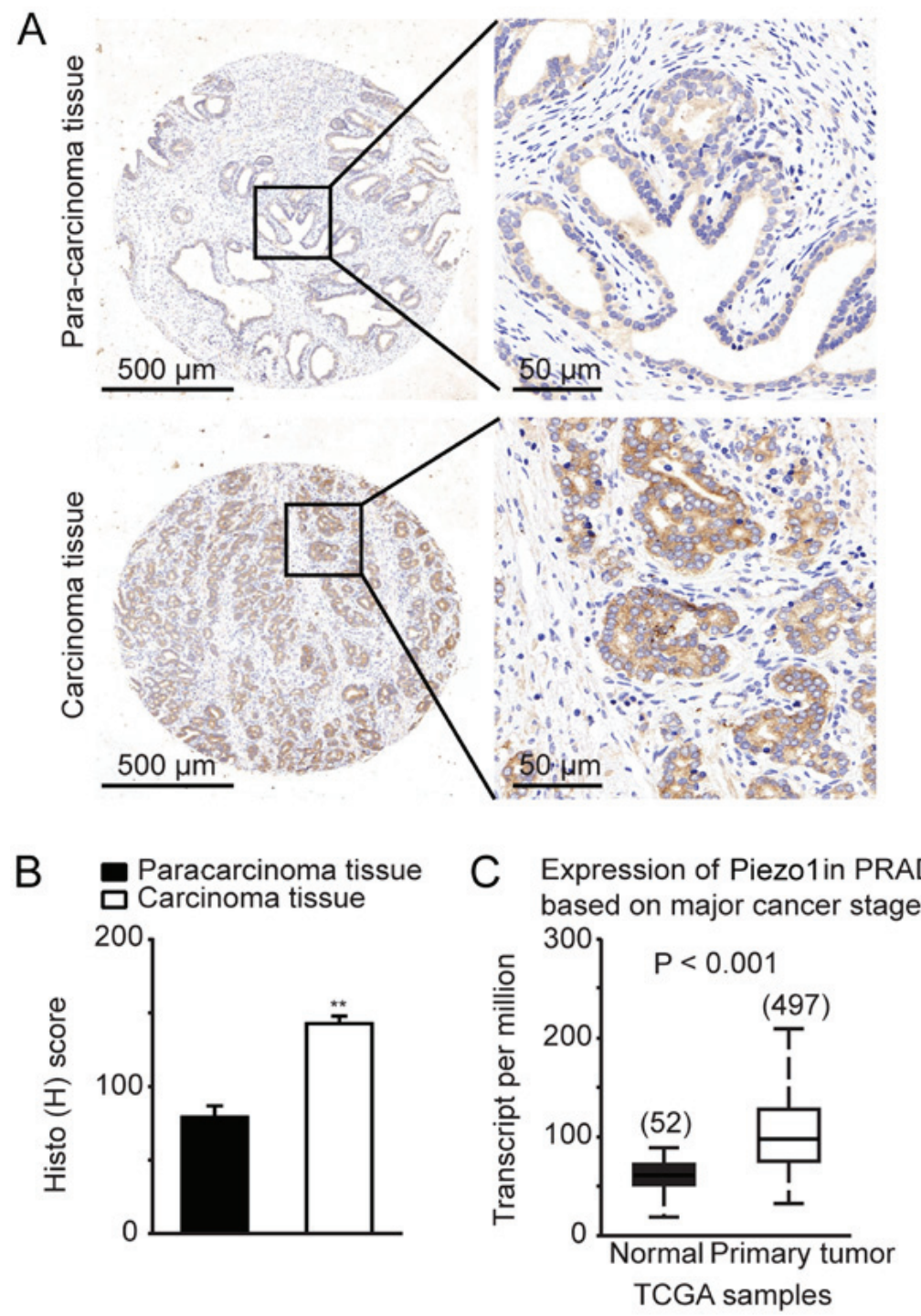

Figure 1. Immunostaining of the Piezol channel in human prostate carcinoma and paracarcinoma tissues. (A) Representative immunohistochemistry staining of Piezol (brown color). The right panel was extended from the square in left panel. (B) Summary data of Piezol channel expression in human prostate carcinoma $(n=44)$ and paracarcinoma tissues $(n=26)$. In comparison with paracarcinoma tissue (mean $H$-score $79.22 \pm 7.73)$, the prostate carcinoma tissue (mean H-score 142.90 \pm 5.22) showed a higher expression of Piezo1. (C) Piezo1 mRNA expression in patients with PRAD from the UALCAN database (normal, $\mathrm{n}=52$; primary tumor, $\mathrm{n}=497 ; \mathrm{P}=1.62448 \times 10^{-12}$ ). Data are shown as the mean \pm standard error of the mean. ${ }^{* *} \mathrm{P}<0.01$. $\mathrm{PRAD}$, prostate adenocarcinoma; Piezo1, piezo type mechanosensitive ion channel component 1; TCGA, The Cancer Genome Atlas.

However, only 4 out of 26 cases of human prostate paracarcinoma tissues exhibited upregulation of the Piezol channel, and the remaining 22 cases depicted downregulation of Piezol (Table I). Clinical evidence from the UALCAN (27) database demonstrated upregulation of Piezo1, also known as FAM38A, in human PCa tissues $(n=497)$, which strongly supports the findings of the present study (Fig. 1C).

Similar to the observation that the Piezol channel is upregulated in human PCa tissues, the expression of Piezol at the mRNA level was significantly higher in PC3 and DU145 $\mathrm{PCa}$ cell lines than that in the normal prostate epithelial cell line RWPE-1. The Piezo1 mRNA levels in the PC3 and DU145 cells were 6.5- and 2.8-fold higher than normal RWPE-1 cells, respectively (Fig. 2A). In addition, western blot analysis revealed that the protein level of Piezo1 in the PC3 and DU145 PCa cell lines increased 2.9- and 3.3-fold, respectively, compared to that in RWPE-1 cells (Fig. 2B). To further characterize differences caused by Piezol channel downregulation in PCa cells compared with normal prostate epithelial cells, patch clamp was performed to record the Piezo1 MA currents (Fig. 2E and F). The results showed that Piezol MA current densities in DU145 PCa cells were 10-fold higher than that in RWPE-1 cells at a displacement stimulation of $9 \mu \mathrm{m}$ (Fig. 2E and F).

Lentiviral vectors expressing Piezol shRNA1, Piezo1 shRNA2 or control shRNA were constructed to knockdown the expression of Piezo1 in DU145 PCa cells. After transfection with Piezol shRNA1 or Piezo1 shRNA2, the mRNA levels of Piezo1 decreased by $55.2 \%$ and $47.5 \%$, respectively, compared to the control shRNA (Fig. 2C). The protein expression level of Piezo1 decreased by 52.1 and $50.7 \%$, respectively, compared to control shRNA (Fig. 2D). The shRNA1-mediated Piezo1 knockdown also dramatically reduced MA current densities in DU145 PCa cells (Fig. 2E and F). These results showed that the Piezol channel is upregulated in human PCa tissues and cell lines, suggesting that Piezol may have an important role in the tumorigenesis of PCa. 
A

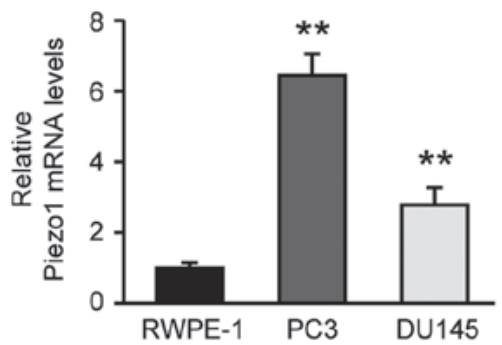

D
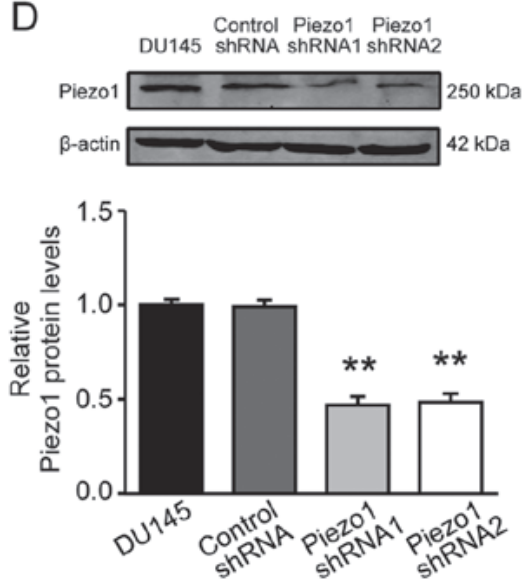
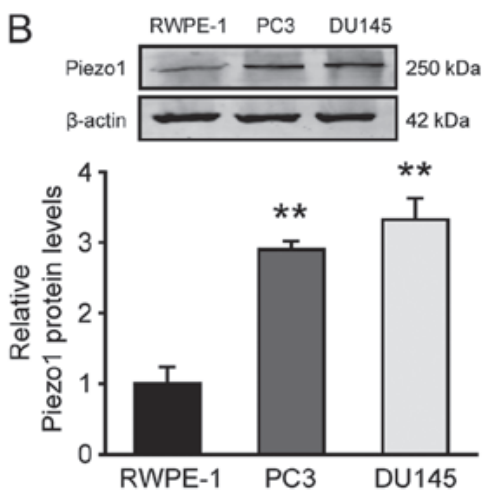

E

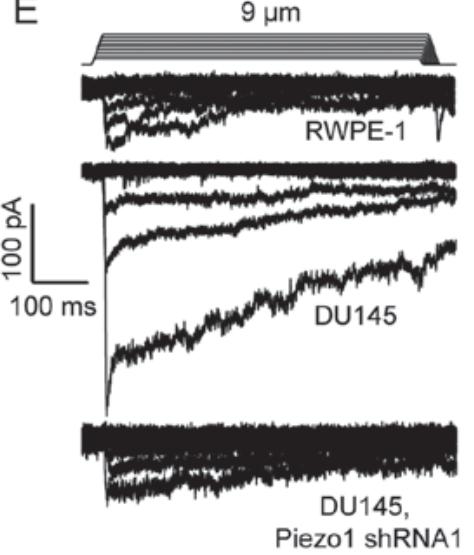

C

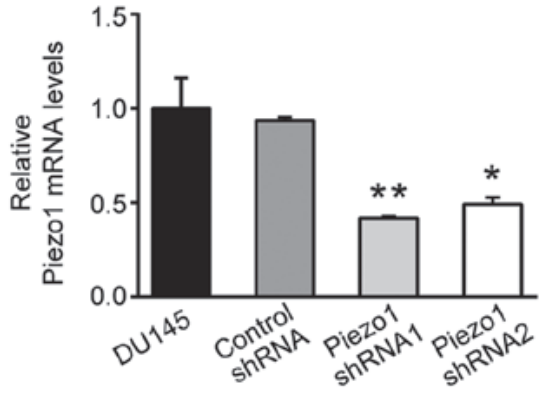

$\mathrm{F}$

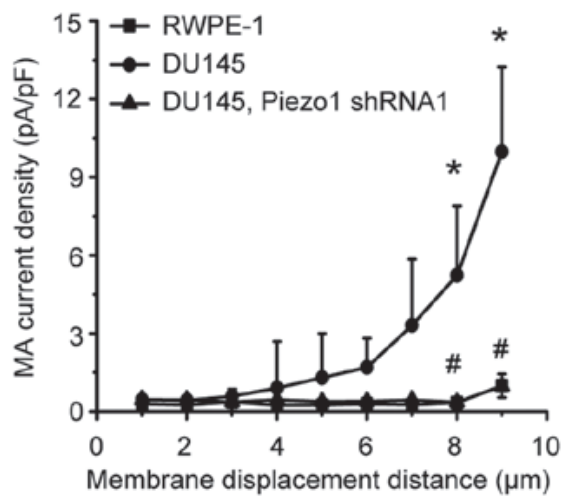

Figure 2. Expression of Piezol channel in human normal prostate epithelial and prostate cancer cell lines. Comparison of Piezo1 at (A) mRNA levels and at (B) protein levels between human normal RWPE-1 cell line, and PC-3 and DU145 prostate cancer cell lines. ${ }^{* *} \mathrm{P}<0.01$ vs. RWPE-1. PC-3 and DU145 prostate cancer cell lines showed significant higher Piezol expression compared with RWPE-1 cells. Knockdown of Piezol channel by shRNA significantly decreased the expression of Piezol at the (C) mRNA and (D) protein levels in the DU145 cell line. ${ }^{*} \mathrm{P}<0.05$ and ${ }^{* *} \mathrm{P}<0.01$ vs. control shRNA. (n=3). (E) Representative Piezo1 MA current in RWPE-1, DU145 and DU145 cells after Piezo1 channel knockdown. The Piezol MA current was evoked by a stimulus probe with a series of poking displacementsteps. (F) Summary data of Piezo1 MA current density with different displacement distances in RWPE-1, DU145 and DU145 Piezo1 shRNA cells ( $\mathrm{n}=8$ in each group). Data are presented as the mean \pm SEM. ${ }^{*} \mathrm{P}<0.05$ RWPE-1 vs. DU145; ${ }^{\#} \mathrm{P}<0.05$ DU145 vs. DU145, Piezo1 shRNA ( $\mathrm{n}=8$ in each group). Piezol, piezo type mechanosensitive ion channel component 1; shRNA, short hairpin RNA; MA, mechanically activated.

A

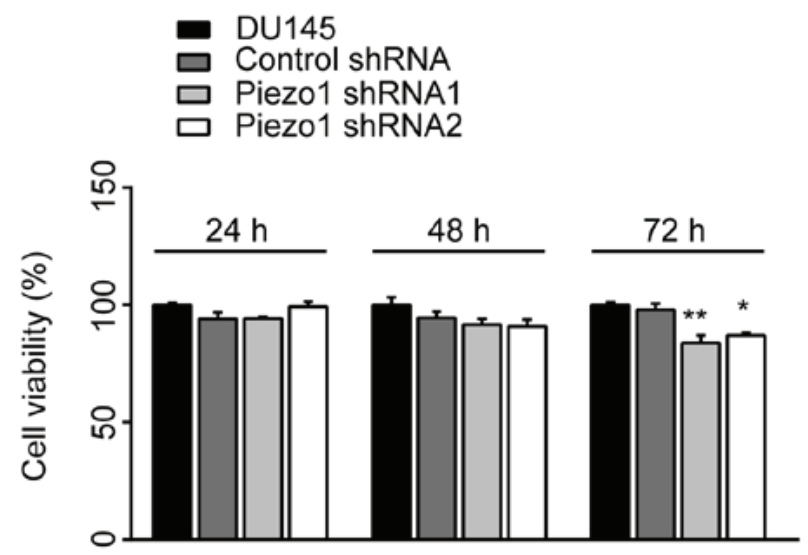

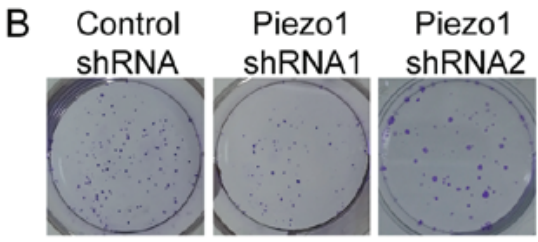

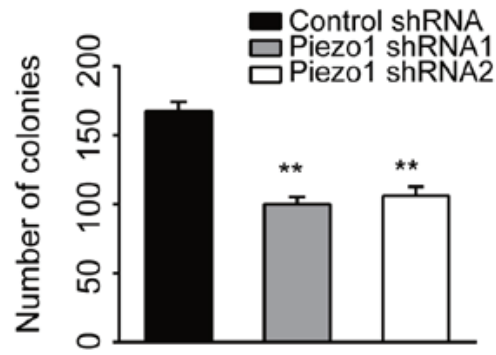

Figure 3. Inhibition of cell proliferation by Piezol downregulation in DU145 prostate cancer cells. (A) Cell viability was evaluated using an MTS assay. Cell viability was quantified by measuring the absorbance at $570 \mathrm{~nm}$. (B) Representative images and summary data of the cell colony formation assay. Data are presented as the mean \pm SEM. ${ }^{*} \mathrm{P}<0.05$ and ${ }^{* *} \mathrm{P}<0.01$ vs. control shRNA. shRNA, short hairpin RNA.

Knockdown of Piezol channel expression or inhibition of Piezol channel activity reduces the proliferation and migration of $\mathrm{PCa}$ cells in vitro. To determine whether the Piezol channel has an important role in PCa progression, its effect was evaluated on cell proliferation and migration in vitro. The results of the MTS assay revealed a significant decrease in the proliferation 
A
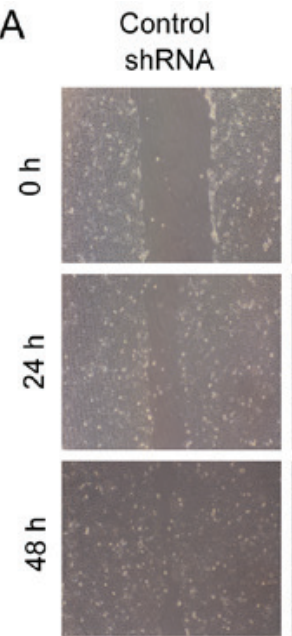

Piezo1

shRNA1
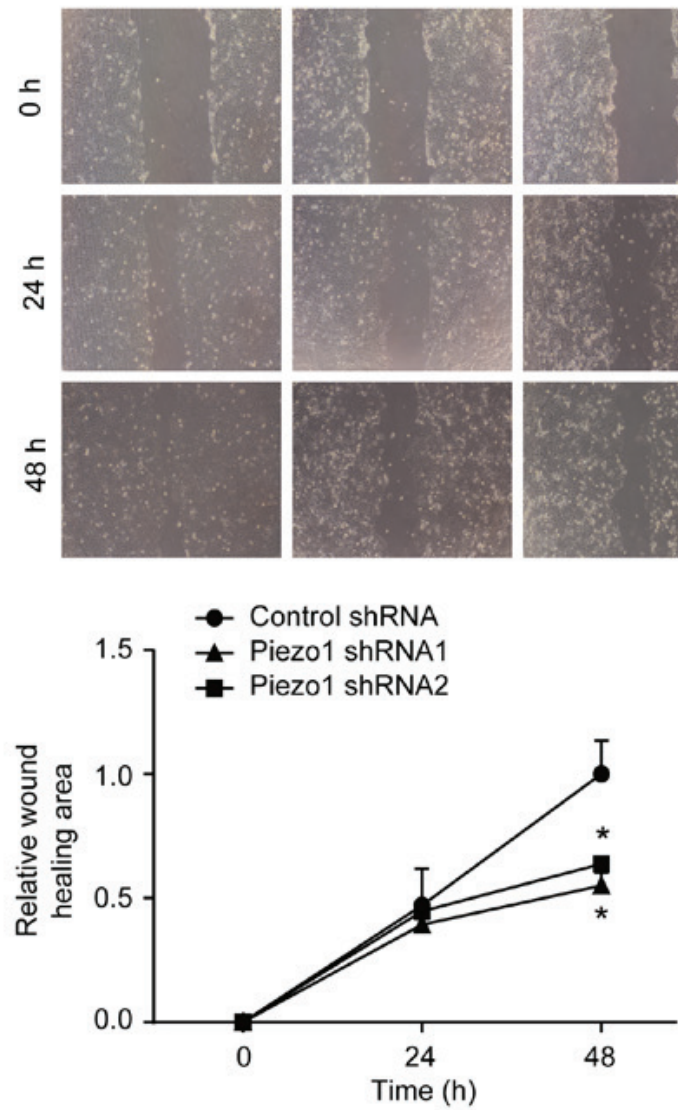

C
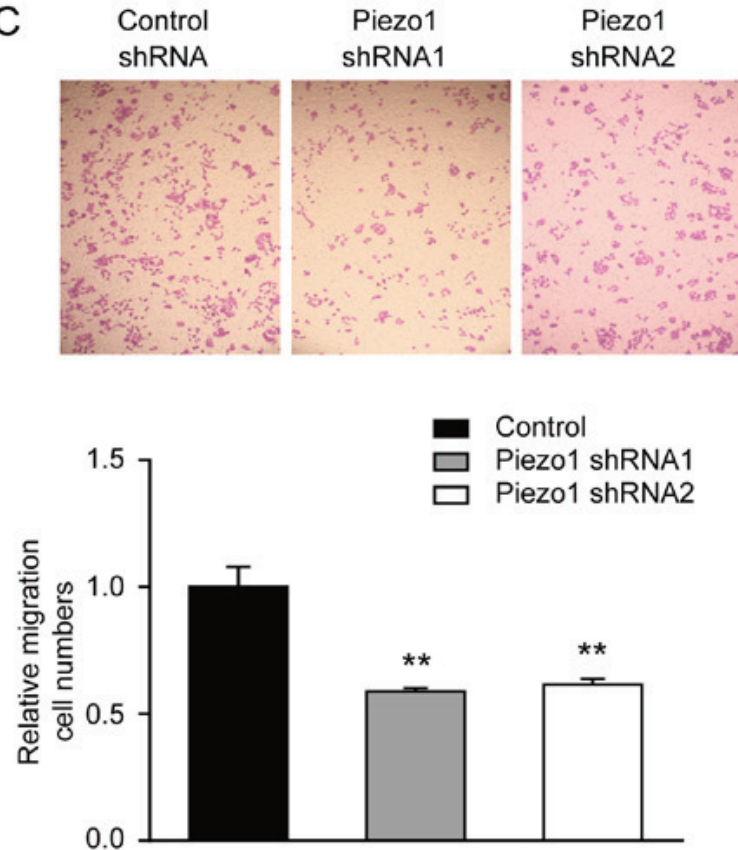

B
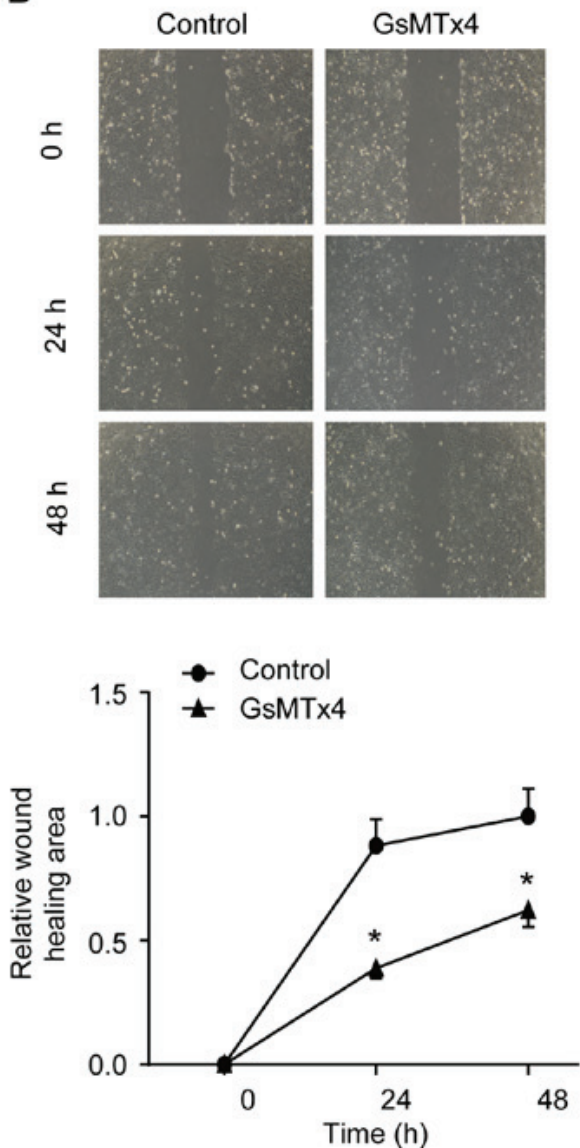

D
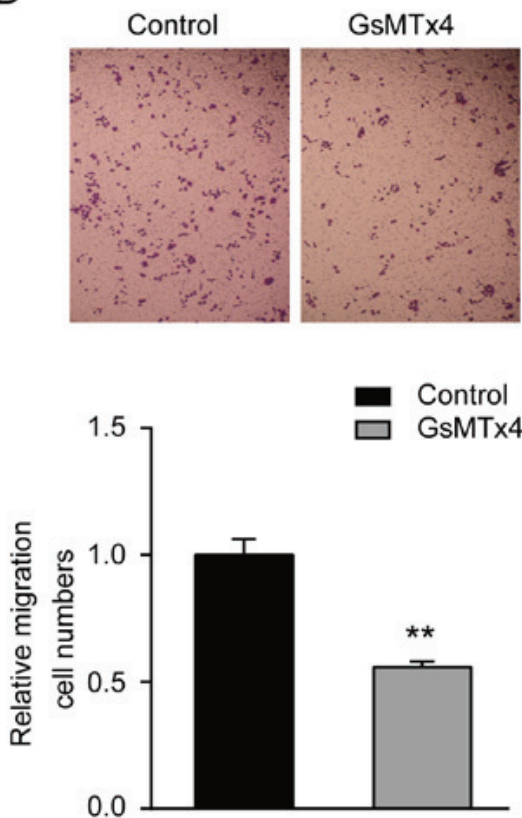

Figure 4. Inhibition of cell migration by Piezo1 downregulation in DU145 prostate cancer cells. Wound healing assay showed that the cell migration of DU145 cells was inhibited either by (A) shRNA knockdown of Piezol or (B) via the Piezol channel antagonist GsMTx4. Similar results were obtained with the Transwell ${ }^{\circledast}$ assays using (C) shRNA knockdown of Piezol or (D) via the Piezol channel antagonist GsMTx4. Data are presented as the mean \pm SEM (n=3). ${ }^{*} \mathrm{P}<0.05$ and ${ }^{* *} \mathrm{P}<0.01$ vs. control. shRNA, short hairpin RNA; Piezo1, piezo type mechanosensitive ion channel component 1.

of DU145 PCa cells following Piezo1 shRNA1 or Piezo1 shRNA2 transfection $(\mathrm{P}<0.05$; Fig. 3A). The antiproliferative effect of Piezol knockdown was also confirmed with the colony formation assay on DU145 PCa cells. Colony formation significantly decreased by $40.2 \%$ in the Piezol shRNA1 group and $36.7 \%$ in the Piezo1 shRNA2 group (Fig. 3B).

The wound-healing assay was performed to test the effect of Piezol on wound closure/cell migration. As shown in Fig. 4, 
A



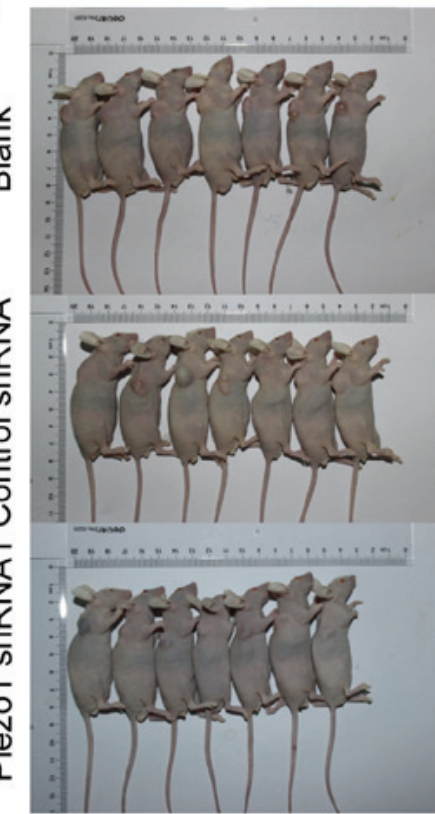

D

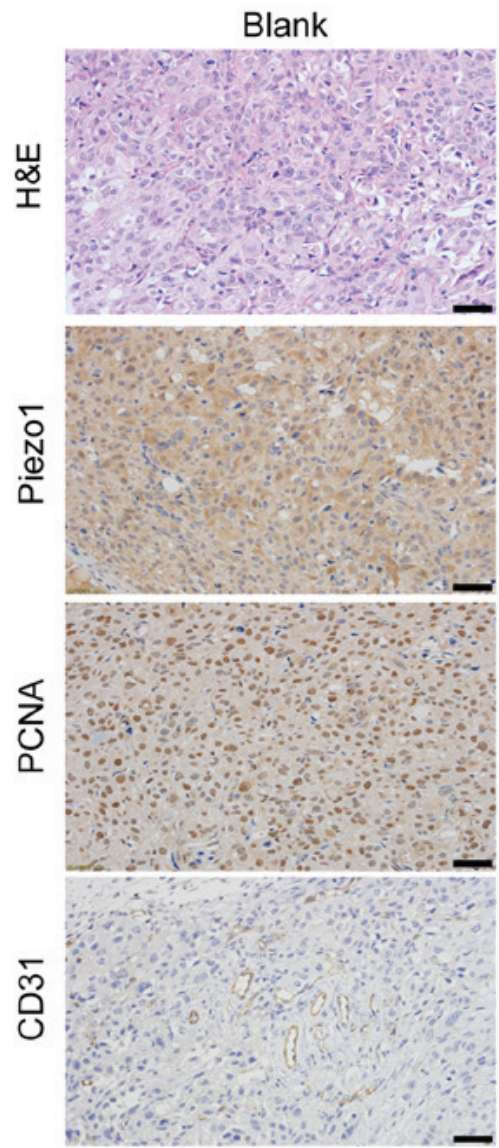

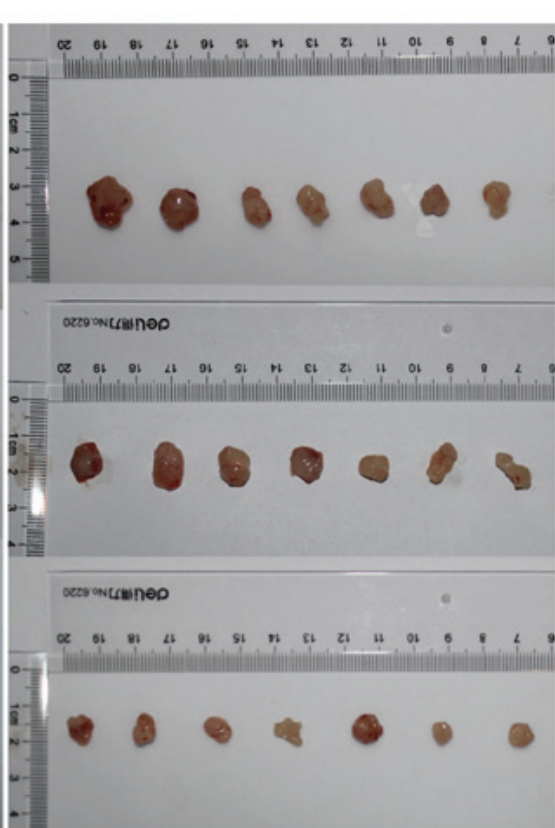

Control shRNA
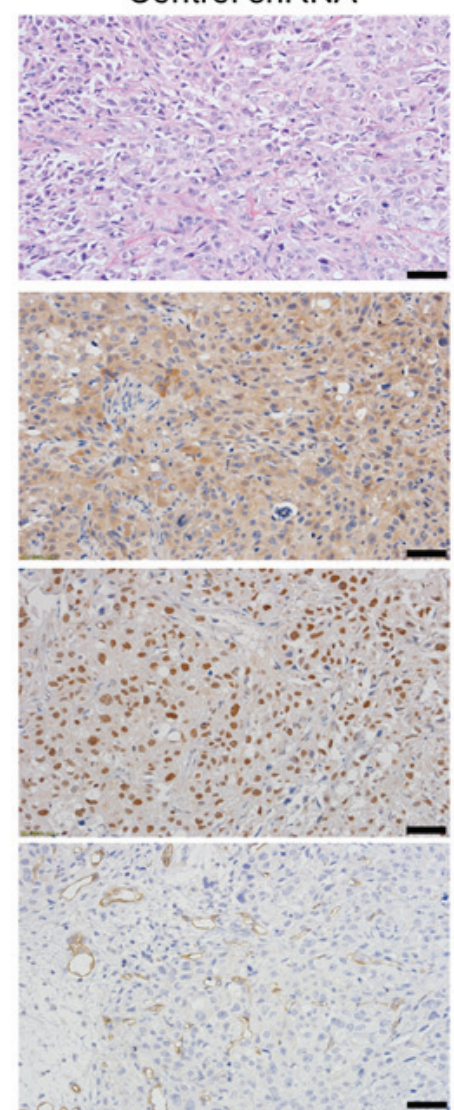

$\mathrm{B}$

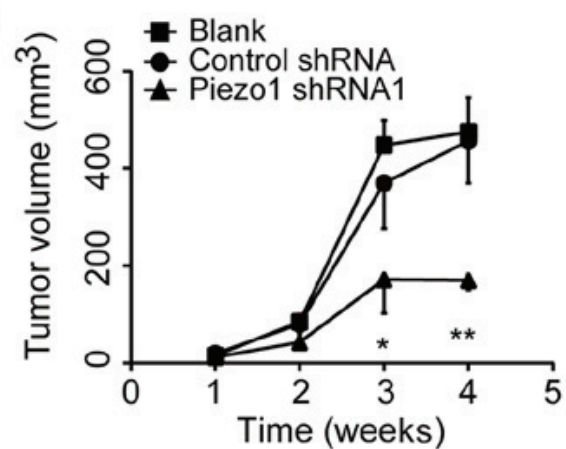

C

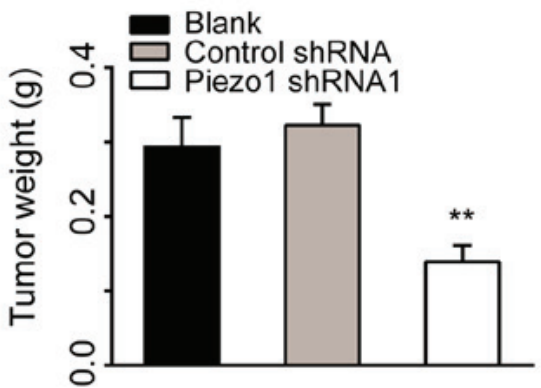

Piezo1 shRNA1
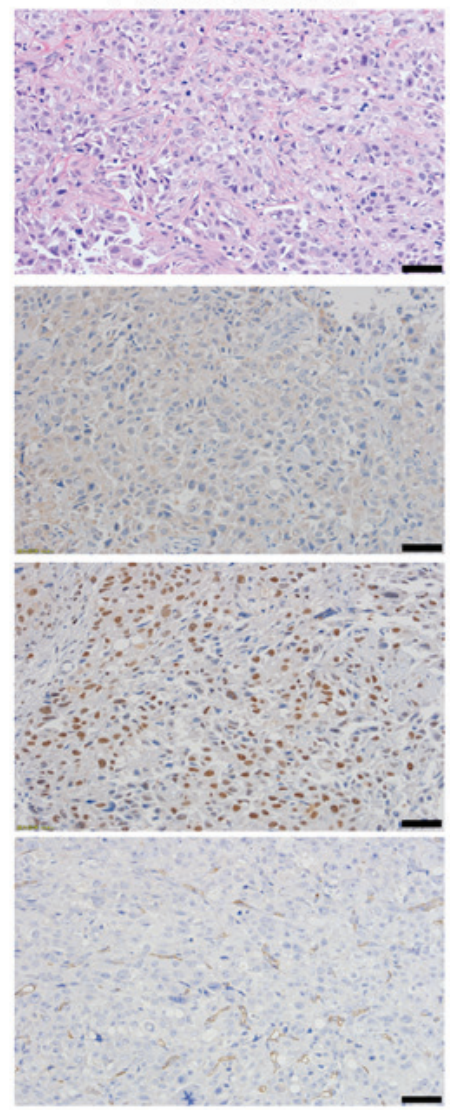

Figure 5. Inhibition of prostate cancer xenograft tumor growth by downregulation of Piezol in vivo. (A) The left panel of image shows the nude mice carrying implanted tumors grown from wild-type DU145 cells (blank), stable DU145 cells infected with control shRNA and Piezo1 shRNA1. The right panel shows the tumors isolated from mice of each group on the 28 th day of generation. (B) Tumor volume growth curve measured with calipers every 7 days ( $\mathrm{n}=7$ ) (C) Measurements of tumor weights from nude mice on the 28th day ( $\mathrm{n}=7$ ). (D) HE staining of xenograft tumors, and immunostaining of Piezo1, PCNA and CD31 in wild-type DU145, control shRNA DU145 and Piezo1 shRNA1 DU145 groups. The expression of Piezo1, PCNA and CD31 were significantly decreased by Piezo1 shRNA1 interference. Scale bar, $50 \mu \mathrm{m}$. Data are presented as the mean \pm SEM. ${ }^{*} \mathrm{P}<0.05$ and ${ }^{* *} \mathrm{P}<0.01$ vs. blank. shRNA, short hairpin RNA; Piezo1, piezo type mechanosensitive ion channel component 1; HE, hematoxylin-eosin; PCNA, proliferating cell nuclear antigen; CD31, platelet and endothelial cell adhesion molecule 1 .

Piezol knockdown by shRNA1 and shRNA2 reduced wound healing of DU145 PCa cells by 55.1 and 44.1\%, respectively, at $48 \mathrm{~h}$, while wound closure was complete in the control shRNA group at $48 \mathrm{~h}$ (Fig. 4A). GsMTx4, a relatively specific 
inhibitor of Piezol channel (28), also reduced wound healing in DU145 PCa cells by 49.4 and $37.8 \%$ at 24 and 48 h, respectively (Fig. 4B). These results indicated that migration of PCa cells was reduced by both Piezol knockdown and by Piezol channel inhibition. A Transwell ${ }^{\circledR}$ assay was also performed using DU145 PCa cells. Cell migration was also markedly reduced by 41.2 , 38.5 and $44.2 \%$ following Piezo1 shRNA1 transfection, Piezo1 shRNA2 transfection and GsMTx4 treatment, respectively (Fig. 4C and D). Taken together, the knockdown of Piezo1 channel expression or its inhibition resulted in a reduction of PCa cell proliferation and migration, suggesting that Piezol may have oncogenic functions in $\mathrm{PCa}$.

Piezol knockdown or inhibition reduces xenograft prostate tumor growth in vivo. To determine the role of Piezol channel in the growth of prostate tumors and the effect of its inhibition during tumor development, two experiments were designed.

DU145 PCa cells and cells expressing control shRNA or Piezo1 shRNA1 were subcutaneously inoculated into immunodeficient mice. The distinct tumor growth induced by implanting DU145 PCa cells into nude mice is shown in Fig. 5A. Piezol shRNA silencing led to a significant reduction in tumor growth (Fig. 5A-C). Both tumor volume and weight, the latter measured after removal from mice, were reduced by Piezol shRNA silencing (Fig. 5A-C). The tumor volume in the Piezol shRNA1 group was reduced by $61.6 \%$ by the 3 rd week and $64.2 \%$ by the 4 th week (Fig. 5A and B). Tumor weight in the Piezo1 shRNA1 group was decreased by $56.9 \%$ by the 4th week (Fig. 5A and C). The HE staining in Fig. 5D illustrates tumor development in the blank, control shRNA and Piezo1 shRNA1 groups. Further IHC staining for Piezo1 indicated that its expression was markedly reduced in the shRNA1 group (Fig. 5D). PCNA, which is a specific marker indicating the proliferation potential of PCa cells (29), was significantly reduced in the Piezol shRNA1 group (Fig. 5D). Moreover, staining of tumor angiogenesis using anti-CD31, a biomarker of endothelial cells (16), was significantly reduced in the Piezo1 shRNA1 group (Fig. 5D). Knockdown of Piezo1 caused a reduction in CD31 levels in prostate tumor cells, which was consistent with the findings of a previous study showing that Piezol knockout decreases the proliferation and integration of endothelial cells (16). These data suggest that the Piezo1 channel may promote the growth of prostate tumors. The knockdown of Piezol expression at the initial stages of PCa may have inhibited the growth of the xenograft prostate tumor in vivo.

Additionally, to avoid the inaccuracies caused by manual measurements of tumor volume, fluorescein-labeled DU145/Luc PCa cells were used for bioluminescence imaging to observe tumor growth in mice. Furthermore, to eliminate the possibility that inhibition of prostate tumor growth was due to the non-specific cell damage caused by Piezol shRNA silencing in the initial stage, Piezol shRNA injections or GsMTx4 treatment were performed during prostate tumor growth. After implantation of fluorescein-labeled DU145/Luc PCa cells for 17 days, four out of five groups of mice were treated with AAV-piezo1-shRNA1-DsRed2, AAV-DsRed2, saline or GsMTx4 on the 18th, 20th, 22nd, 24th and 28th day, whereas mice in another group were not treated (blank). On the 17th day, the photon counts showed no significant differences among the five groups (Fig. 6A and B). However, in the three subsequent weeks, the increase of photon counts in the GsMTx4 group were significantly lower than that of the $\mathrm{NaCl}$ or blank group, and the photon counts of the Piezo1 shRNA1 group were dramatically lower than that of the control shRNA group (Fig. 6A and B). To verify whether the bioluminescence imaging technology accurately reflects tumor size, tumors were stripped and weighed on the 38th day. Consistent with bioluminescence imaging results, tumor weight was markedly lower following treatment with GsMTx4 or with Piezo1 shRNA1 injections (Fig. 6C and D). Thus, both bioluminescence images and tumor growth revealed that Piezol knockdown or the inhibition of Piezol channel activity significantly suppressed prostate tumor growth. HE and IHC staining revealed that Ki-67, a specific marker of cell proliferation (29), was downregulated by Piezol shRNA treatment (Fig. S1).

Taken together, these results suggest that the Piezo1 knockdown and its inhibition may have suppressed tumor growth, not only at the initial stage but also later in the developmental process of PCa. All these data further illustrate that Piezo1 is a potential treatment target for $\mathrm{PCa}$.

Knockdown of Piezol expression inhibits Yodal-and mechanical stimulation-induced intracellular calcium signals. Piezol channel is a mechanically activated cation channel that allows $\mathrm{Ca}^{2+}$ to pass through and enter cells $(12,30)$. Moreover, $\mathrm{Ca}^{2+}$ is a well-known modulator cancer cell proliferation, differentiation and migration, and has an important role in tumorigenesis $(31,32)$. To determine the role of the Piezo1 channel in intracellular calcium signaling, calcium imaging was performed in PCa DU145 cells in control shRNA and Piezo1 shRNA1 group. The calcium levels associated with the treatment with the Piezol channel activator Yodal and the mechanically induced calcium signals were measured in both groups. Mechanical stimulation-induced calcium signals in Piezo1 shRNA1 DU145 cells were markedly lower than that in the control shRNA DU145 cells. The AUC of the fluorescence curve in the Piezol shRNA1 group was significantly smaller than that in the control shRNA group (Fig. 7A and B). Yoda1-induced calcium signals in Piezo1 shRNA1 DU145 cells were also markedly lower than that in control shRNA DU145 cells. The AUC of the fluorescence curve in the Piezol shRNA1 group was significantly smaller than that in the control shRNA group (Fig. 7C and D). These results suggested that calcium signals are elicited via Piezol channel-mediated $\mathrm{Ca}^{2+}$ influx in PCa cells. Moreover, Piezo1 knockdown significantly inhibits mechanical stimulation- or Yoda1-elicited intracellular calcium signals.

Akt/mTOR signaling is involved in downstream events of Piezol activation. The ERK and Akt/mTOR signaling pathways are major molecular mechanisms involved in cell survival, proliferation, motility and differentiation (33). Both pathways can be regulated by intracellular $\mathrm{Ca}^{2+}$ signals (33-36). To determine the molecular mechanisms underlying the Piezo1-dependent PCa development, the involvement of ERK and/or Akt/mTOR pathway in the downstream events of Piezol activation were evaluated. The results of the GENMED PI3K kinase activity assay showed 


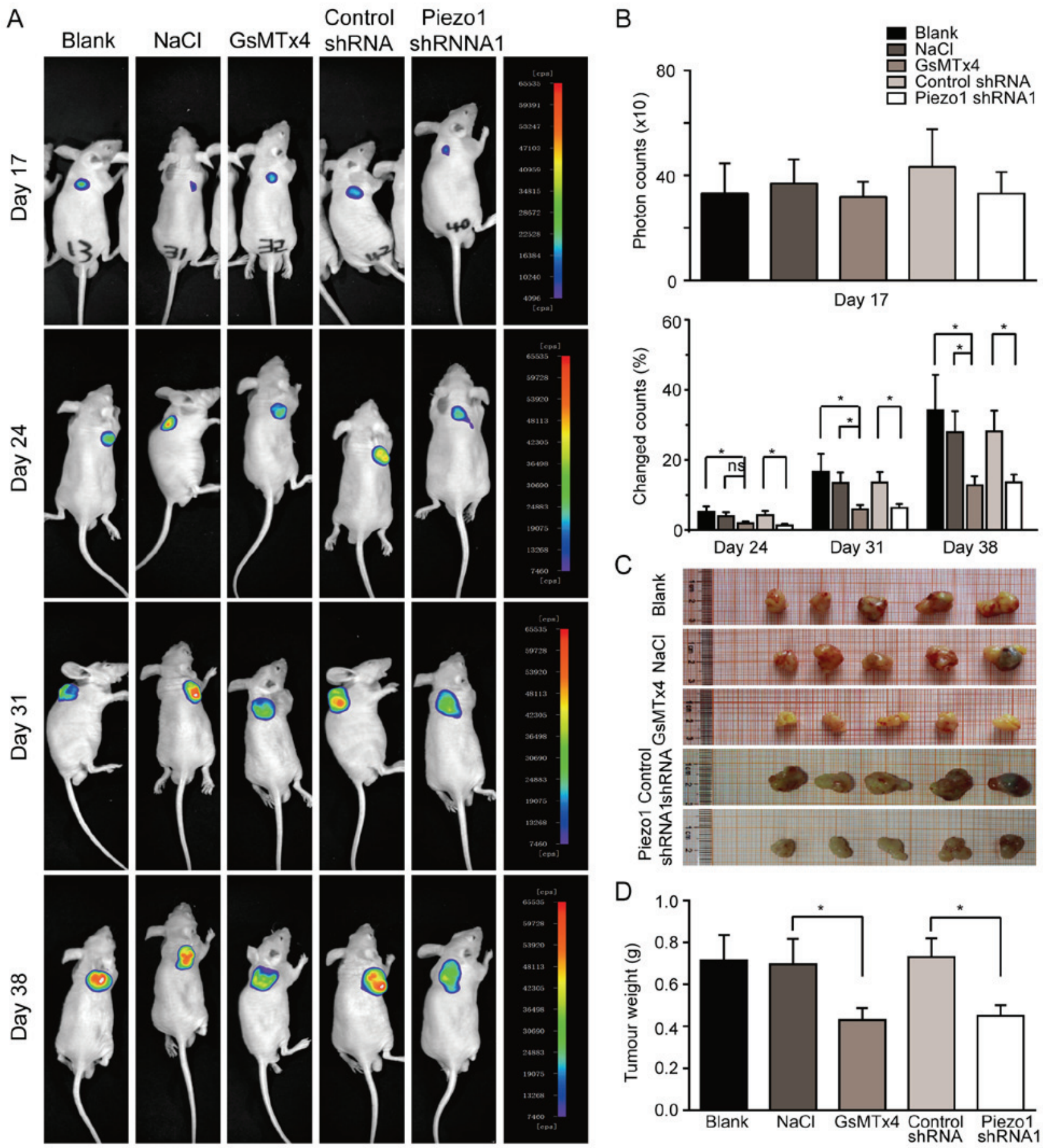

Figure 6. Inhibition of prostate cancer xenograft tumor growth by downregulation of Piezol in vivo. (A) Representative images of DU145/Luc xenograft tumor mice before (day 17, implanted for 17 days) and after (days 24, 31, and 38, implanted for 24, 31 and 38 days, respectively) treatment with saline, GsMTx4, AAV-DsRed2 or AAV-piezo1-shRNA-DsRed2. (B) The photon counts before (day 17) intratumoral treatment (top panel) and the altered photon counts after (day 24, 31 and 38) intratumoral treatment (botto panel). (C) Tumors were isolated from nude DU145/Luc xenograft prostate tumor mice in each group on day 38. (D) Measurements of tumor weight from tumors collected from nude DU145/Luc xenograft mice in each group on the day 38. Data are presented as the mean \pm SEM. ${ }^{*} \mathrm{P}<0.05$. DU145/Luc, luciferase-labeled DU145 cells; shRNA, short hairpin RNA; Piezol, piezo type mechanosensitive ion channel component 1 ; ns, not significant.

that there were no significant differences in PI3K kinase activity between the Piezol shRNA1 group and the control shRNA group (Fig. 8A). Western blot analysis showed that the level of PI3K, Akt and mTOR was not changed, but the levels of p-Akt (Ser473) and p-mTOR (Ser2448) markedly decreased in a PI3K-independent manner after knockdown of Piezol channel by Piezo1 shRNA1 interference (Fig. 8B-I).
The levels of p-Akt and p-mTOR decreased by $34.6 \%$ and $37.6 \%$, respectively (Fig. 8E and H). The ratios of p-Akt/Akt and $\mathrm{p}-\mathrm{mTOR} / \mathrm{mTOR}$ were also markedly decreased after knockdown of Piezol channel (Fig. 8F and I). However, the expression of ERK1/2 and p-ERK1/2 (Thr202/Tyr204) did not show any significant differences between the Piezol shRNA1 and the control shRNA groups (Fig. 8J and K). The ratio of 
A
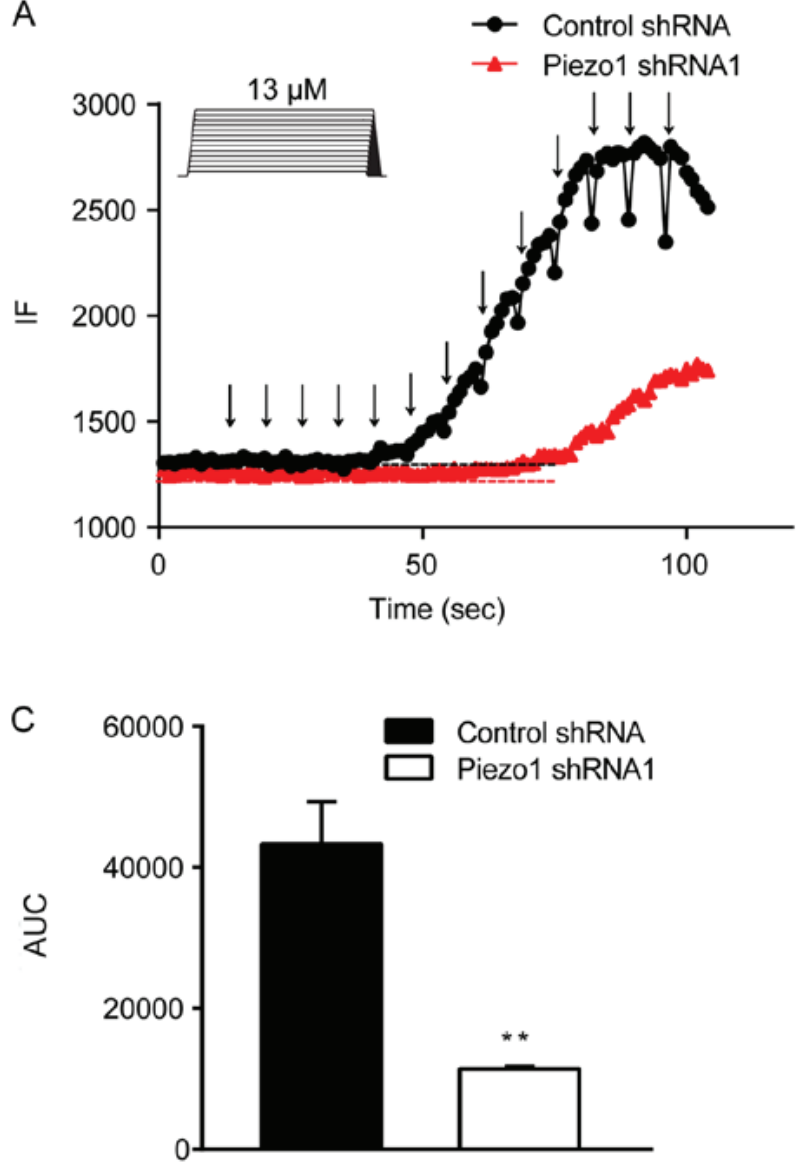

B
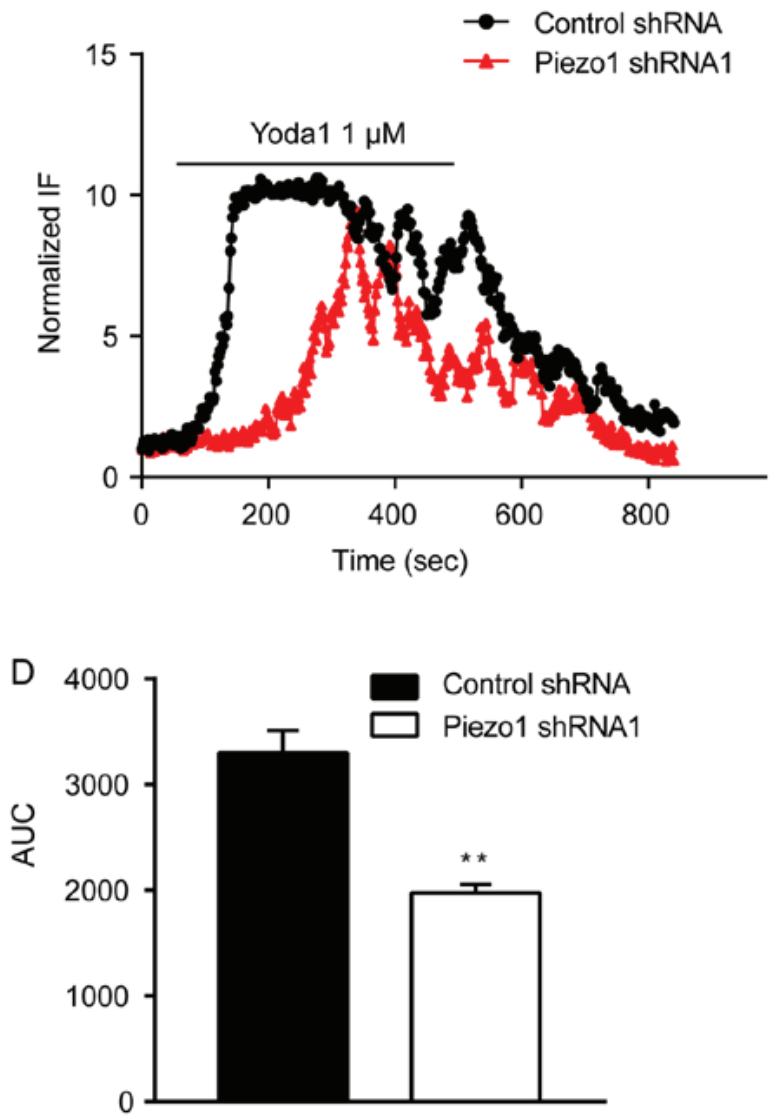

Figure 7. The effect of Piezo1 knockdown on calcium signals induced by mechanical stimulation and the specific Piezol channel agonist Yoda1. Analysis of dynamic $\mathrm{Ca}^{2+}$ signals induced by mechanical stimulation (A) and by Yoda1 (B) between control shRNA (Black) and Piezol shRNA group (Red). (C and D) The AUC in different groups was calculated and compared. Data are presented as the mean \pm SEM. ${ }^{* *} \mathrm{P}<0.01$ vs. control shRNA. shRNA, short hairpin RNA; Piezo1, piezo type mechanosensitive ion channel component 1; IF, intracellular fluorescence; AUC, area under the curve.

p-ERK/ERK did not show any significant difference after knockdown of Piezol channel (Fig. 8L). Taken together, these data suggested that Piezol knockdown may have inhibited PCa cell proliferation, migration and prostate tumor growth by blocking Akt/mTOR phosphorylation.

Knockdown of Piezol inhibits cell cycle progression of $\mathrm{PCa}$ cells in vitro. In addition to regulating the above signaling pathways, $\mathrm{Ca}^{2+}$ plays an important role throughout the cell cycle and is especially important early in $G_{1}$, particularly for the $\mathrm{G}_{1} / \mathrm{S}$ and $\mathrm{G}_{2} / \mathrm{M}$ transitions (31). Flow cytometry analysis was performed to determine the role of Piezol in the cell cycle progression of DU145 PCa cells. The results showed that the proportion of cells in the $G_{0} / G_{1}$ phase significantly increased, whereas cells in the $S$ phase significantly decreased in the Piezol shRNA1 group compared to the control shRNA group (Fig. 9A and B). This result indicated that inhibition of Piezol expression caused $\mathrm{G}_{1}$ phase arrest. CDK4, cyclin D1 and the cyclin D1-CDK4 complex are the key effectors in regulation of cell cycle transition from $\mathrm{G}_{1}$ to the $\mathrm{S}$ phase (31). Therefore, the expression levels of cyclin D1 and CDK4 were evaluated by western blotting in DU145 PCa cells. Compared with the control shRNA group, the expression of CDK4 and cyclin D1 proteins considerably decreased with Piezol shRNA1 interference (Fig. 9C and D). The expression of CDK4 and cyclin D1 decreased by 45.0 and $26.2 \%$, respectively (Fig. 9C and D). Taken together, these results indicated that the downregulation of Piezol in DU145 PCa cells may have led to their arrest at the $G_{0} / G_{1}$ phase by inhibiting the expression of cyclin D1 and CDK4.

\section{Discussion}

The major findings of the present study are as follows: i) Piezol is overexpressed in PCa cell lines and in human PCa tissues; ii) downregulation of Piezol significantly reduced PCa cell proliferation and migration in vitro, and inhibited prostate tumor growth in vivo; iii) Piezol-dependent $\mathrm{Ca}^{2+}$ signals were generated in PCa cells; iv) Piezol downstream signaling may have involved Akt/mTOR, but not ERK1/2; and v) Piezol-dependent promotion of $\mathrm{PCa}$ cell transition from $G_{1}$ to $S$ phase may be associated with PCa progression. Based on these findings, upregulation of Piezol in PCa may mediate an increase in $\mathrm{Ca}^{2+}$ signals. Subsequently, increased intracellular $\mathrm{Ca}^{2+}$ may activate Akt/mTOR signaling pathways, upregulating the expression of cyclin D1 and CDK4 and promoting the assembly of the cyclin D1-CDK4 complex. These cellular events may, therefore, have promoted $\mathrm{PCa}$ cell proliferation and migration, leading to prostate tumor growth (Fig. 10). The present results have shown for the first 
A

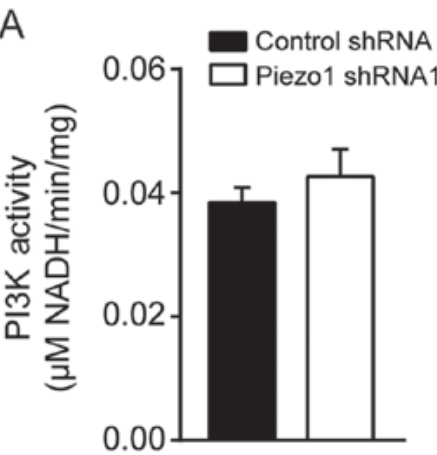

D

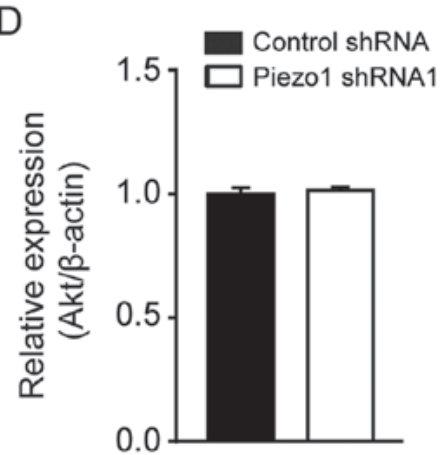

G
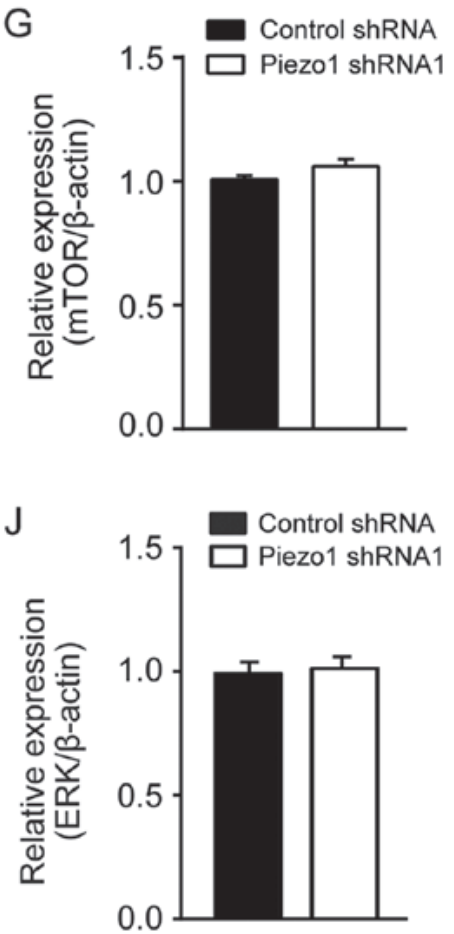

$B$

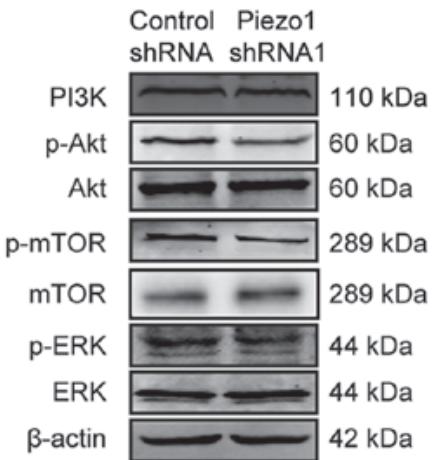

E

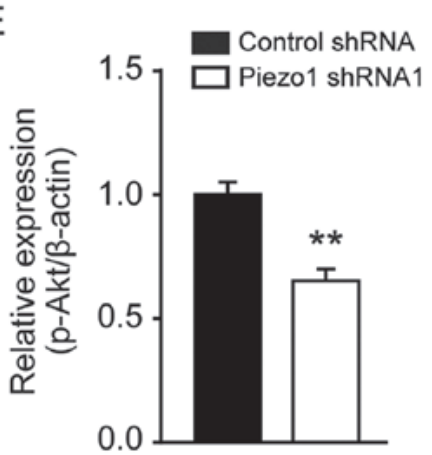

$\mathrm{H}$

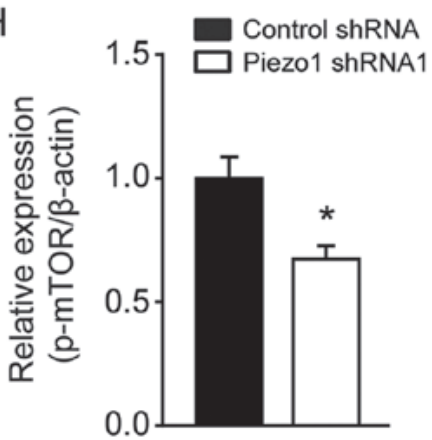

K

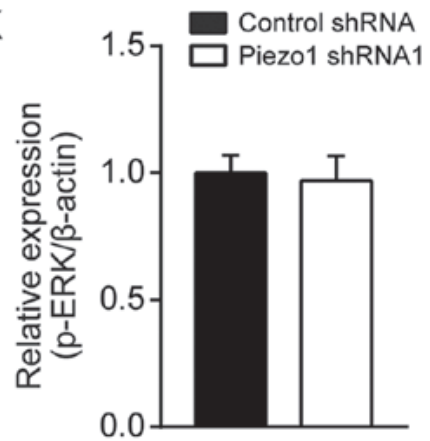

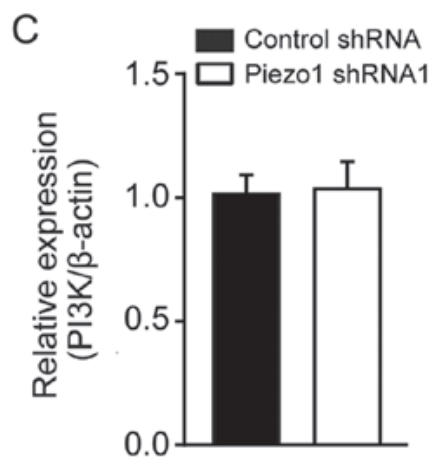

$\mathrm{F}$
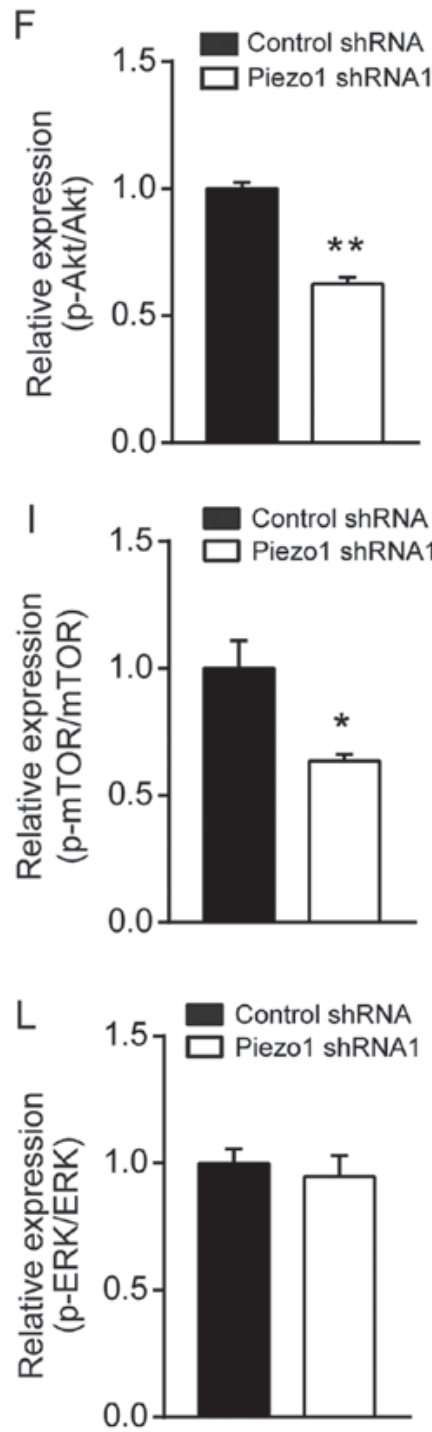

Figure 8. Downstream signals involved in Piezol channel activation in DU145 prostate cancer cells. (A) The activity of PI3K was detected by GENMED PI3K Assay Kit based on the NADH levels. (B) Representative western blot assay used to evaluate the potential downstream signaling molecules associated with Piezol activation. Densitometry analysis of (C) PI3K, (D) Akt, (E) p-Akt, (F) p-Akt/Akt, (G) mTOR, (H) p-mTOR, (I) pmTOR/mTOR, (J) ERK, (K) p-ERK and (L) p-ERK/ERK. Data are presented as the mean \pm SEM $(n=4)$. ${ }^{*}<0.05$ and ${ }^{* *} \mathrm{P}<0.01$ vs. control. shRNA, short hairpin RNA; Piezo1, piezo type mechanosensitive ion channel component 1; p-, phosphorylated-.

time (to the best of our knowledge) that the Piezol channel and its downstream signaling pathway may have an important role in the tumorigenesis of human $\mathrm{PCa}$. These findings may also have several clinical implications. First, given that it is overexpressed in PCa cells and tissues, Piezol may potentially serve as a biomarker for the diagnosis and prognosis of $\mathrm{PCa}$.
Second, both in vitro and in vivo studies indicate that Piezol may potentially be used as a therapeutic target for human PCa. Third, the development of small molecules that selectively inhibit Piezol may be a useful pharmacological intervention for the treatment of $\mathrm{PCa}$ or other cancers where Piezol is overexpressed. 
A

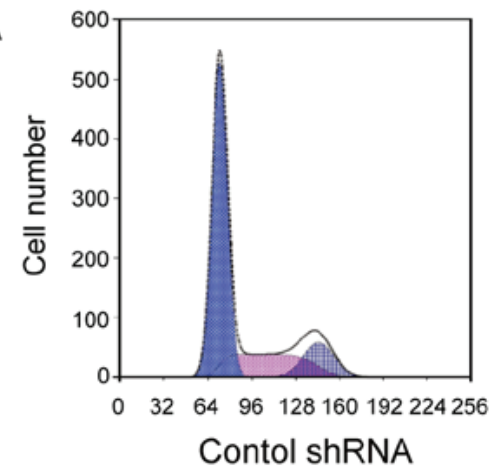

C

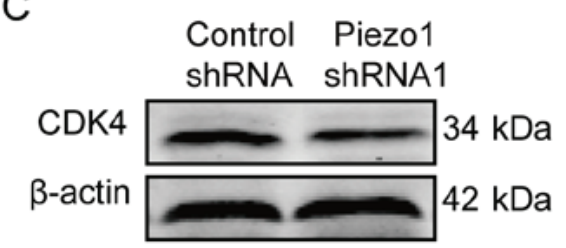

Cyclin D1

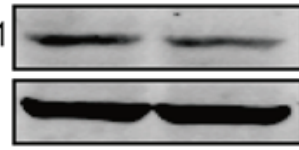

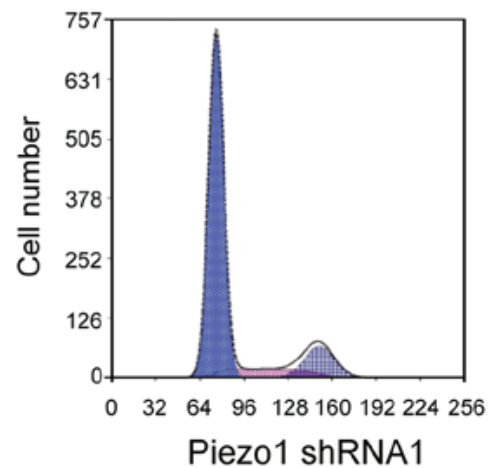
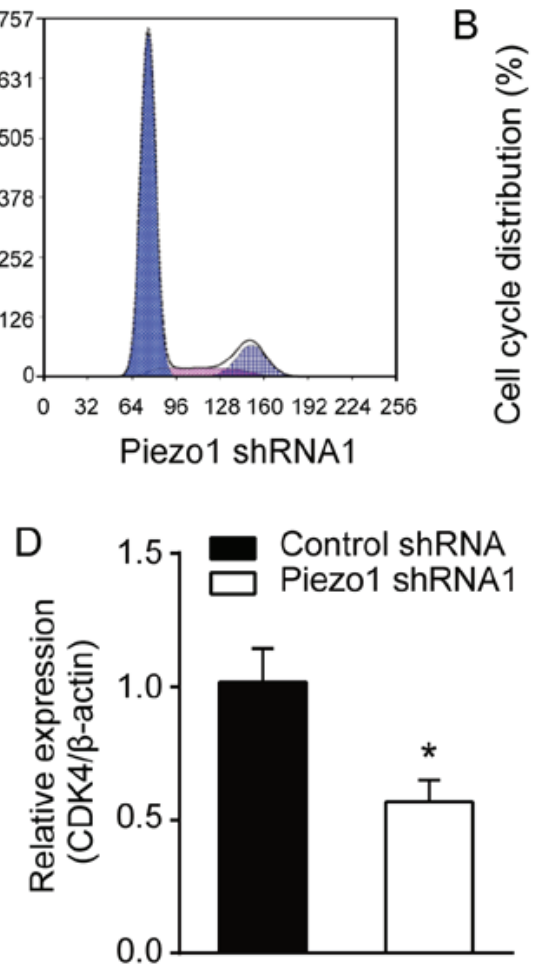
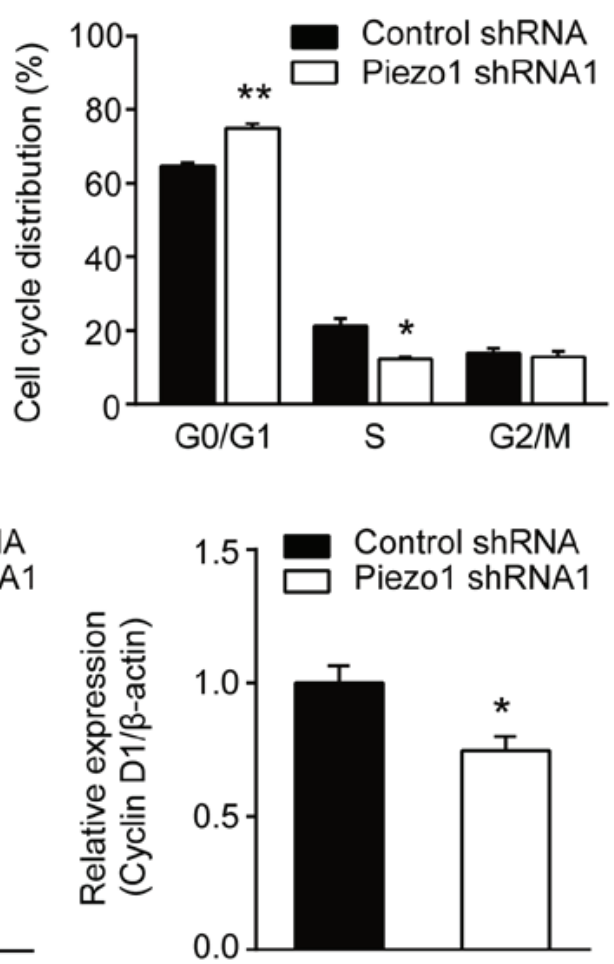

Figure 9. Inhibition of cell cycle progression by Piezol knockdown in DU145 prostate cancer cells. (A) Flow cytometric analysis and (B) quantification of the cell cycle distribution of the DU145 prostate cancer cell line transfected with control or Piezo shRNA1. Bar graphs show an increase in the number of cells in the $\mathrm{G}_{0} / \mathrm{G}_{1}$ phase, and a decrease in cells in the $\mathrm{S}$ phase after Piezo1 silencing ( $\mathrm{n}=3$ ). (C) Western blot analysis and (D) densitometry of CDK4 and cyclin D1 $(\mathrm{n}=4)$. Both CDK4 and cyclin D1 were downregulated following Piezo1 knockdown. Data are presented as the mean $\pm \mathrm{SEM}$. ${ }^{*}<0.05$ and ${ }^{* *} \mathrm{P}<0.01$. shRNA, short hairpin RNA; Piezo1, piezo type mechanosensitive ion channel component 1.

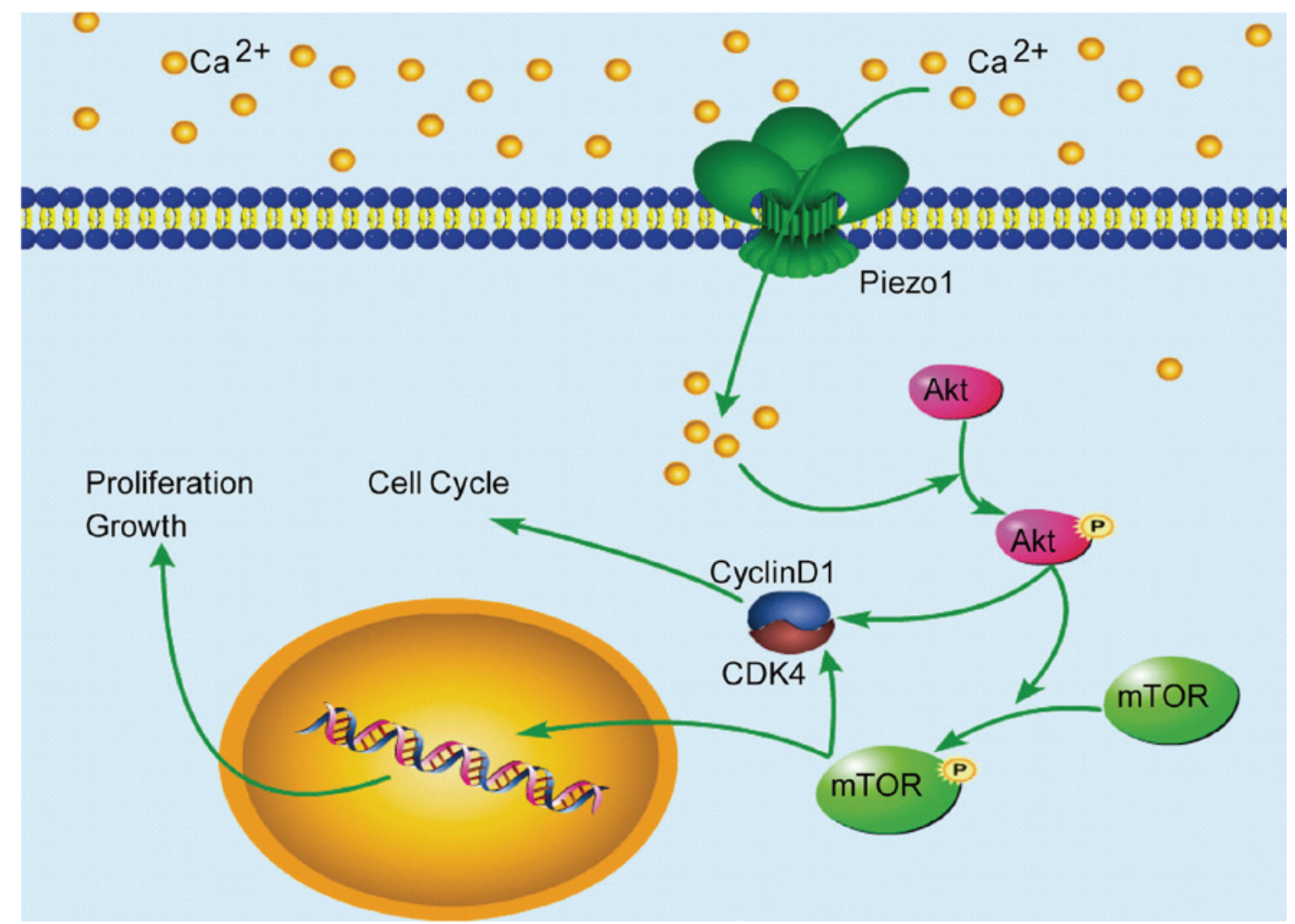

Figure 10. Piezol promotes tumorigenesis of prostate cancer. High expression of Piezo1 channel and its activation may induce Ca ${ }^{2+}$ influx. Subsequently, intracellular $\mathrm{Ca}^{2+}$ increase directly or indirectly activates Akt, mTOR, upregulating the expression of cyclin D1 and CDK4. Phosphorylation of Akt and mTOR, followed by activation of the cyclin D1/CDK4 complex, may facilitate cell survival, cell cycle progression, cell proliferation and migration, which in turn may promote the tumorigenesis of prostate cancer. 
Some studies have revealed that Piezol is implicated in human cancer diseases. Piezol functions as a TFF1-binding protein, promoting TFF1-mediated migration and invasion of gastric cancer cells (22). The overexpression of Piezo1, accompanied by an increased expression of $\beta 1$ integrin, also contributes to the migration of gastric cancer cells (22). In addition, Piezol is overexpressed in malignant MCF-7 breast epithelial cancer cells. Breast cancer patients with upregulated Piezo1 have higher hazard ratios and shorter overall survival time (37). More recently, Chen et al (38) reported that Piezo1 is localized in focal adhesions and may activate integrin-focal adhesion kinase signaling, regulating extracellular matrix associated pathways and reinforcing tissue stiffness. In turn, a stiffer mechanical microenvironment may lead to the upregulation of Piezo1, further promoting glioma aggression. In accordance with these studies, the present findings showed that Piezol expression levels are relatively higher in human PCa tissues and cancer cells compared with normal tissues and epithelial cells. High expression of Piezol may have promoted the progression of PCa, although the underlying signaling mechanisms are distinct from those described in previous studies. However, the present results also contradict previous findings: McHugh et al (39) described that depletion of the Piezol, which was localized to the endoplasmic reticulum, inactivated $\beta 1$ integrin affinity and reduced HeLa cell adhesion, and its knockout promoted the migration of lung epithelial cells. In addition, loss-of-function germline mutations in Piezol have been identified in some patients with colorectal adenomatous polyposis (40). Further research into the association between Piezol and cancer is required.

Piezol channel mediates $\mathrm{Ca}^{2+}$ influx when it receives mechanical stimulation $(30,41)$. Similar to these previous studies, the present experiments demonstrated that activation of Piezo1 channel by mechanical stimulation or Yoda1 treatment mediated $\mathrm{Ca}^{2+}$ influx in PCa cells. Knocking down the expression of Piezol reduced the calcium signals elicited by mechanical stimulation or the agonist Yoda1. $\mathrm{Ca}^{2+}$ is a very important second messenger that triggers various cellular biofunctions. The ERK and Akt/mTOR signaling pathways play a key role in tumorigenesis, and their activation and activity are regulated by intracellular $\mathrm{Ca}^{2+}$ signals $(33-36,42)$. In the present study, the Akt/mTOR, but not ERK1/2, signaling pathway was activated in DU145 PCa cells in a Piezo1-dependent manner: Silencing Piezol significantly reduced the phosphorylation levels of Akt and mTOR. Consistent with these findings, a previous study showed that Piezol is required for the phosphorylation of Akt in endothelial cells in response to shear stress induced by blood flow (43). Akt is generally activated by membrane phosphatidylinositol- $(3,4,5)-\mathrm{P}_{3}$, a substrate of PI3K $(33,44)$. However, in the present study, Piezo1-mediated Akt activation was independent from PI3K activity, as the knockdown of Piezol did not change the expression levels of PI3K in DU145 PCa cells. Consistent with these results, $\mathrm{Ca}^{2+}$ influx mediated by NMDA- or AMPA-type glutamate receptors or voltage-gated $\mathrm{Ca}^{2+}$ channels, is also known to activate Akt in a PI3K-independent manner (45-48). The Piezo1-dependent activation of Akt may involve calmodulin (CaM) and CaM-dependent protein kinase II (CaMKII), which are activated by $\mathrm{Ca}^{2+}$. $\mathrm{Ca}^{2+} / \mathrm{CaMKII}$ activation of Akt plays an important role in regulating cell survival and apoptosis $(35,36)$.
Further research into whether $\mathrm{Ca}^{2+} / \mathrm{CaM} / \mathrm{CaMKII}$ signals are induced by Piezo1 activation is required. However, the dynamic calcium signals recorded in the present study is limited since it cannot accurately mimic the intracellular calcium signals responding to the microenvironment of cancerous tissues. Further research for measuring spontaneous calcium events in PCa cells is required.

ERK1/2 can be activated by $\mathrm{Ca}^{2+}$ influx produced by stretch-opened Piezol channels, which in turn promotes epithelial cell proliferation (20). In dental pulp stem cells, ERK1/2 can be activated in a Piezol-dependent manner by the mechanical force of low-intensity pulsed ultrasound (49). However, in the present study, the ERK does not appear to be involved in the downstream signaling pathway of Piezol activation in DU145 PCa cells. Inhibiting the expression of Piezol did not change the phosphorylation levels of ERK1/2. The exact mechanisms underlying Piezol-induced activation of Akt/mTOR, but not ERK in DU145 PCa cells are not clear. A negative feedback regulation between Akt and ERK pathways may explain this phenomenon, especially since ERK activation can be negatively regulated by Akt-mediated Raf phosphorylation, which is the upstream activator of ERK $(33,50)$.

$\mathrm{Ca}^{2+}$ plays a key role in cell cycle regulation. The activation of cyclin D1 and CDK4, and the assembly of cyclin D1-CDK4 complexes are essential for promoting cell cycle transition from $\mathrm{G}_{1}$ to $\mathrm{S}$ phase (31). The present study showed that the activation of cyclin D1 and CDK4 is suppressed, and the cell cycle may, therefore, be arrested at $G_{0} / G_{1}$ phase after Piezol knockdown in DU145 PCa cells. Piezo1-mediated $\mathrm{Ca}^{2+}$ influx and its downstream signaling pathways may increase the expression of cyclin D1 and CDK4, and the assembly of cyclin D1-CDK4 complexes in PCa cells. Moreover, Piezol-induced activation of Akt may promote PCa cell transition from $G_{1}$ to $S$ phase by activating cyclin D1, since Akt can stabilize mature cyclin D1 $(31,51)$. Thus, the Piezol knockdown may have inactivated Akt, suppressed cyclin D1 activation and arrested cells in $\mathrm{G}_{1}$ phase.

In the present study, Piezol shRNA only caused $\sim 50 \%$ knockdown of Piezo1 mRNA and proteins, but the Piezo1 MA current densities were nearly abolished in the shRNA-treated PCa cells. This result indicates that knockdown of Piezo1 monomer may have markedly disturbed Piezo1 homotrimer assembly. Additionally, as the MTS assay showed that knockdown of Piezol only induced a mild suppression in cell viability, but it induced $\sim 50 \%$ reduction on the tumor size in the xenograft tumor growth experiment. One reason is that cell proliferation conforms to an exponential growth pattern, short-term cell viability observation in vitro cannot accurately match long-term xenograft tumor growth in vivo, the other possibility is that knockdown of Piezol may inhibit tumor growth by inhibiting tumor angiogenesis since knockdown of Piezo1 significantly reduced the expression of vascular endothelial marker CD31 in tumor tissues.

In summary, the present study found that the Piezol channel was upregulated in PCa cells, at the mRNA and protein levels. The Piezol channel was also upregulated in human PCa tissues. Piezo1-dependent activation of the Akt/mTOR signaling pathway and acceleration of cell cycle progression may have contributed to the tumorigenesis of $\mathrm{PCa}$. Furthermore, downregulation of Piezol may have suppressed 
the proliferation and migration of $\mathrm{PCa}$ cells in vitro and inhibited prostate tumor growth in vivo. The present study clearly indicates that the Piezol channel has a crucial role in PCa tumorigenesis. Piezo1 may also serve as a biomarker of PCa and could be used as a novel therapeutic target in the treatment of human $\mathrm{PCa}$.

\section{Acknowledgements}

Not applicable.

\section{Funding}

This work is supported by National Natural Science Foundation of China (NSFC, 81571080 to ZJ, and 81573416 to WZ), Natural Science Foundation of Hebei Province (H2015206240 to ZJ), Science and technology research project of Hebei colleges (ZD2017053 to ZJ), the Ministry of Education (Young Thousand Talent Program to WZ) and High Talent Science Research Project of Education Bureau Hebei Province (A2017010068 to WZ).

\section{Availability of data and materials}

The datasets used and/or analyzed during the current study are available from the corresponding author on reasonable request.

\section{Authors' contributions}

ZJ and YZ designed the research. YH, CL, DZ, HM, LH, QG, SW, YG performed the research. YH, WZ and ZJ analyzed the data. ZJ, YH, WZ and YZ wrote the manuscript. All authors read and approved the final manuscript.

\section{Ethics approval and consent to participate}

The study was approved by the Ethics Committee of Hebei Medical University, and was performed in accordance with the approved guidelines.

\section{Patient consent for publication}

Not applicable.

\section{Competing interests}

The authors declare that they have no competing interests.

\section{References}

1. Fitzmaurice C, Allen C, Barber RM, Barregard L, Bhutta ZA, Brenner H, Dicker DJ, Chimed-Orchir O, Dandona R, Dandona L, et al: Regional, and national cancer incidence, mortality, years of life lost, years lived with disability, and disability-adjusted life-years for 32 cancer groups, 1990 to 2015: A systematic analysis for the global burden of disease study. JAMA Oncol 3: 524-548, 2017.

2. Siegel RL, Miller KD and Jemal A: Cancer Statistics, 2017. CA Cancer J Clin 67: 7-30, 2017.

3. Bostwick DG,Burke HB, Djakiew D, Euling S,Ho SM,Landolph J, Morrison H, Sonawane B, Shifflett T, Waters DJ, et al: Human prostate cancer risk factors. Cancer 101 (Suppl): 2371-2490, 2004.
4. DeMarzo AM, Nelson WG, Isaacs WB and Epstein JI: Pathological and molecular aspects of prostate cancer. Lancet 361: 955-964, 2003.

5. Howard N, Clementino M, Kim D, Wang L, Verma A, Shi X, Zhang Z and DiPaola RS: New developments in mechanisms of prostate cancer progression. Semin Cancer Biol: Sep 10, 2018 (Epub ahead of print): S1044-579X(18)30079-8, 2018.

6. Butcher DT, Alliston T and Weaver VM: A tense situation: Forcing tumour progression. Nat Rev Cancer 9: 108-122, 2009.

7. Yu H, Mouw JK and Weaver VM: Forcing form and function: Biomechanical regulation of tumor evolution. Trends Cell Biol 21: 47-56, 2011.

8. Hoyt K, Castaneda B, Zhang M, Nigwekar P, di Sant'agnese PA, Joseph JV, Strang J, Rubens DJ and Parker KJ: Tissue elasticity properties as biomarkers for prostate cancer. Cancer Biomark 4: 213-225, 2008.

9. Hegarty PK, Watson RW, Coffey RN, Webber MM and Fitzpatrick JM: Effects of cyclic stretch on prostatic cells in culture. J Urol 168: 2291-2295, 2002.

10. Wadhera P: An introduction to acinar pressures in BPH and prostate cancer. Nat Rev Urol 10: 358-366, 2013.

11. Sottnik JL, Dai J, Zhang H, Campbell B and Keller ET: Tumor-induced pressure in the bone microenvironment causes osteocytes to promote the growth of prostate cancer bone metastases. Cancer Res 75: 2151-2158, 2015.

12. Coste B, Mathur J, Schmidt M, Earley TJ, Ranade S, Petrus MJ, Dubin AE and Patapoutian A: Piezo1 and Piezo2 are essential components of distinct mechanically activated cation channels. Science 330: 55-60, 2010.

13. Wu J, Lewis AH and Grandl J: Touch, tension, and transduction - the function and regulation of Piezo ion channels. Trends Biochem Sci 42: 57-71, 2017.

14. Ranade SS, Woo SH, Dubin AE, Moshourab RA, Wetzel C, Petrus M, Mathur J, Bégay V, Coste B, Mainquist J, et al: Piezo2 is the major transducer of mechanical forces for touch sensation in mice. Nature 516: 121-125, 2014.

15. Ikeda R, Cha M, Ling J, Jia Z, Coyle D and Gu JG: Merkel cells transduce and encode tactile stimuli to drive $\mathrm{A} \beta$-afferent impulses. Cell 157: 664-675, 2014.

16. Li J, Hou B, Tumova S, Muraki K, Bruns A, Ludlow MJ, Sedo A, Hyman AJ, McKeown L, Young RS, et al: Piezol integration of vascular architecture with physiological force. Nature 515: 279-282, 2014

17. Nonomura K, Woo SH, Chang RB, Gillich A, Qiu Z, Francisco AG, Ranade SS, Liberles SD and Patapoutian A: Piezo2 senses airway stretch and mediates lung inflation-induced apnoea. Nature 541: 176-181, 2017.

18. Murthy SE, Dubin AE and Patapoutian A: Piezos thrive under pressure: Mechanically activated ion channels in health and disease. Nat Rev Mol Cell Biol 18: 771-783, 2017.

19. Ranade SS, Qiu Z, Woo SH, Hur SS, Murthy SE, Cahalan SM, Xu J, Mathur J, Bandell M, Coste B, et al: Piezol, a mechanically activated ion channel, is required for vascular development in mice. Proc Natl Acad Sci USA 111: 10347-10352, 2014.

20. Gudipaty SA, Lindblom J, Loftus PD, Redd MJ, Edes K, Davey CF, Krishnegowda V and Rosenblatt J: Mechanical stretch triggers rapid epithelial cell division through Piezol. Nature 543: 118-121, 2017.

21. He L, Si G, Huang J, Samuel ADT and Perrimon N: Mechanical regulation of stem-cell differentiation by the stretch-activated Piezo channel. Nature 555: 103-106, 2018.

22. Yang XN, Lu YP, Liu JJ, Huang JK, Liu YP, Xiao CX, Jazag A, Ren JL and Guleng B: Piezol is as a novel trefoil factor family 1 binding protein that promotes gastric cancer cell mobility in vitro. Dig Dis Sci 59: 1428-1435, 2014.

23. Zhang T, Chi S, Jiang F, Zhao Q and Xiao B: A protein interaction mechanism for suppressing the mechanosensitive Piezo channels. Nat Commun 8: 1797, 2017.

24. Livak KJ and Schmittgen TD: Analysis of relative gene expression data using real-time quantitative PCR and the 2(-Delta Delta C(T)) Method. Methods 25: 402-408, 2001.

25. Shah RB and Zhou M: Recent advances in prostate cancer pathology: Gleason grading and beyond. Pathol Int 66: 260-272, 2016.

26. Booy EP, Henson ES and Gibson SB: Epidermal growth factor regulates Mcl-1 expression through the MAPK-Elk-1 signalling pathway contributing to cell survival in breast cancer. Oncogene 30: 2367-2378, 2011.

27. Chandrashekar DS, Bashel B, Balasubramanya SAH, Creighton CJ, Ponce-Rodriguez I, Chakravarthi BVSK and Varambally S: UALCAN: A portal for facilitating tumor subgroup gene expression and survival analyses. Neoplasia 19: 649-658, 2017. 
28. Bae C, Sachs F and Gottlieb PA: The mechanosensitive ion channel Piezol is inhibited by the peptide GsMTx4. Biochemistry 50: 6295-6300, 2011.

29. Zhong W, Peng J, He H, Wu D, Han Z, Bi X and Dai Q: Ki-67 and PCNA expression in prostate cancer and benign prostatic hyperplasia. Clin Invest Med 31: E8-E15, 2008.

30. Gnanasambandam R, Bae C, Gottlieb PA and Sachs F: Ionic selectivity and permeation properties of human PIEZO1 channels. PLoS One 10: e0125503, 2015.

31. Roderick HL and Cook SJ: $\mathrm{Ca}^{2+}$ signalling checkpoints in cancer: Remodelling $\mathrm{Ca}^{2+}$ for cancer cell proliferation and survival. Nat Rev Cancer 8: 361-375, 2008.

32. Monteith GR, Prevarskaya N and Roberts-Thomson SJ: The calcium-cancer signalling nexus. Nat Rev Cancer 17: 367-380, 2017.

33. Mendoza MC, Er EE and Blenis J: The Ras-ERK and PI3K-mTOR pathways: Cross-talk and compensation. Trends Biochem Sci 36: 320-328, 2011

34. Agell N, Bachs O, Rocamora N and Villalonga P: Modulation of the Ras/Raf/MEK/ERK pathway by $\mathrm{Ca}^{2+}$, and calmodulin. Cell Signal 14: 649-54.2002.

35. Gocher AM, Azabdaftari G, Euscher LM, Dai S, Karacosta LG Franke TF and Edelman AM: Akt activation by $\mathrm{Ca}^{2+} /$ calmodulin-dependent protein kinase kinase 2 (CaMKK2) in ovarian cancer cells. J Biol Chem 292: 14188-14204, 2017.

36. Zhang R, Zhu Y, Dong X, Liu B, Zhang N, Wang X, Liu L, Xu C Huang $S$ and Chen L: Celastrol Attenuates Cadmium-Induced Neuronal Apoptosis via Inhibiting $\mathrm{Ca}^{2+}-\mathrm{CaMKII-Dependent}$ Akt/mTOR Pathway. J Cell Physiol 232: 2145-2157, 2017.

37. Li C, Rezania S, Kammerer S, Sokolowski A, Devaney $\mathrm{T}$, Gorischek A,Jahn S, HacklH, Groschner K, WindpassingerC, etal: Piezo1 forms mechanosensitive ion channels in the human MCF-7 breast cancer cell line. Sci Rep 5: 8364, 2015.

38. Chen X, Wanggou S, Bodalia A, Zhu M, Dong W, Fan JJ, Yin WC, Min HK, Hu M, Draghici D, et al: A feedforward mechanism mediated by mechanosensitive ion channel PIEZO1 and tissue mechanics promotes glioma aggression. Neuron 100: 799-815. e7, 2018.

39. McHugh BJ, Murdoch A, Haslett $\mathrm{C}$ and Sethi T: Loss of the integrin-activating transmembrane protein Fam38A (Piezo1) promotes a switch to a reduced integrin-dependent mode of cell migration. PLoS One 7: e40346, 2012.

40. Spier I, Kerick M, Drichel D, Horpaopan S, Altmüller J, Laner A, Holzapfel S, Peters S, Adam R, Zhao B, et al: Exome sequencing identifies potential novel candidate genes in patients with unexplained colorectal adenomatous polyposis. Fam Cancer 15: 281-288, 2016
41. Miyamoto T, Mochizuki T, Nakagomi H, Kira S, Watanabe M, Takayama Y, Suzuki Y, Koizumi S, Takeda M and Tominaga M: Functional role for Piezol in stretch-evoked $\mathrm{Ca}^{2}$ influx and ATP release in urothelial cell cultures. J Biol Chem 289: 16565-16575, 2014.

42. Saxton RA and Sabatini DM: mTOR Signaling in growth, metabolism, and disease. Cell 168: 960-976, 2017.

43. Wang S, Chennupati R, Kaur H, Iring A, Wettschureck N and Offermanns S: Endothelial cation channel PIEZO1 controls blood pressure by mediating flow-induced ATP release. J Clin Invest 126: 4527-4536, 2016.

44. Vivanco I and Sawyers CL: The phosphatidylinositol 3-kinase AKT pathway in human cancer. Nat Rev Cancer 2: 489-501, 2002

45. Yano S, Tokumitsu H and Soderling TR: Calcium promotes cell survival through CaM-K kinase activation of the protein-kinase-B pathway. Nature 396: 584-587, 1998.

46. Ishiuchi S, Tsuzuki K, Yoshida Y, Yamada N, Hagimura N, Okado H, Miwa A, Kurihara H, Nakazato Y, Tamura M, et al: Blockage of $\mathrm{Ca}(2+)$-permeable AMPA receptors suppresses migration and induces apoptosis in human glioblastoma cells. Nat Med 8: 971-978, 2002.

47. Ishiuchi S, Yoshida Y, Sugawara K, Aihara M, Ohtani T, Watanabe T, Saito N, Tsuzuki K, Okado H, Miwa A, et al: $\mathrm{Ca}^{2+}$-permeable AMPA receptors regulate growth of human glioblastoma via Akt activation. J Neurosci 27: 7987-8001, 2007.

48. Valerie NC, Dziegielewska B, Hosing AS, Augustin E, Gray LS, Brautigan DL, Larner JM and Dziegielewski J: Inhibition of T-type calcium channels disrupts Akt signaling and promotes apoptosis in glioblastoma cells. Biochem Pharmacol 85: 888-897, 2013.

49. Gao Q, Cooper PR, Walmsley AD and Scheven BA: Role of Piezo channels in ultrasound-stimulated dental stem cells. J Endod 43: 1130-1136, 2017.

50. Zimmermann S and Moelling K: Phosphorylation and regulation of Raf by Akt (protein kinase B). Science 286: 1741-1744, 1999.

51. Diehl JA, Cheng M, Roussel MF and Sherr CJ: Glycogen synthase kinase-3beta regulates cyclin D1 proteolysis and subcellular localization. Genes Dev 12: 3499-3511, 1998.

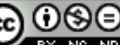

This work is licensed under a Creative Commons Attribution-NonCommercial-NoDerivatives 4.0 International (CC BY-NC-ND 4.0) License. 